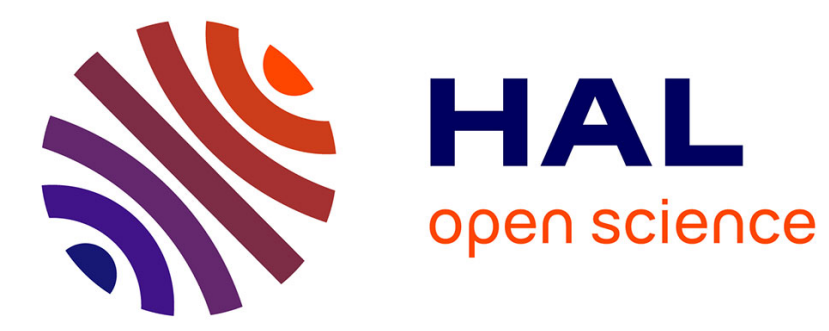

\title{
On the effect of sintering temperature on the fracture energy of an Alumina-Mullite-Zirconia castable at $600^{\circ} \mathrm{C}$
}

R Vargas, X Pinelli, B Smaniotto, François Hild, R B Canto

\section{To cite this version:}

R Vargas, X Pinelli, B Smaniotto, François Hild, R B Canto. On the effect of sintering temperature on the fracture energy of an Alumina-Mullite-Zirconia castable at $600^{\circ} \mathrm{C}$. Journal of the European Ceramic Society, 2021, 41 (7), pp.4406-4418. 10.1016/j.jeurceramsoc.2021.01.023 . hal-03104704

\author{
HAL Id: hal-03104704 \\ https://hal.science/hal-03104704
}

Submitted on 9 Jan 2021

HAL is a multi-disciplinary open access archive for the deposit and dissemination of scientific research documents, whether they are published or not. The documents may come from teaching and research institutions in France or abroad, or from public or private research centers.
L'archive ouverte pluridisciplinaire HAL, est destinée au dépôt et à la diffusion de documents scientifiques de niveau recherche, publiés ou non, émanant des établissements d'enseignement et de recherche français ou étrangers, des laboratoires publics ou privés. 


\section{On the effect of sintering temperature on the fracture energy of an Alumina-Mullite-Zirconia castable at $600^{\circ} \mathrm{C}$}

\author{
R. Vargas ${ }^{a, c}$, X. Pinelli ${ }^{c}$, B. Smaniotto ${ }^{c}$, F. Hild ${ }^{c}$ and R.B. Canto ${ }^{a, b}$ \\ ${ }^{a}$ Federal University of São Carlos, Graduate Program in Materials Science and Engineering (PPGCEM), 13565-905, São Carlos-SP, Brazil \\ ${ }^{b}$ Federal University of São Carlos (UFSCar), Department of Materials Engineering (DEMa), 13565-905, São Carlos-SP, Brazil, Brazil \\ ${ }^{c}$ Université Paris-Saclay, ENS Paris-Saclay, CNRS, LMT - Laboratoire de Mécanique et Technologie, 91190 Gif-sur-Yvette, France
}

\section{ARTICLE INFO}

\section{Keywords:}

High-temperature

Digital Image correlation (DIC)

Wedge Splitting Test (WST)

Crack propagation

Fracture energy

\begin{abstract}
A B S T R ACT
Refractory castables are utilized in hazardous environments and thus their reliability should be accurately evaluated to avoid incidents. This work aims to measure the fracture energy of a high-alumina refractory with mullite-zirconia aggregates at $600^{\circ} \mathrm{C}$. Wedge Splitting Tests were performed on 5 samples with different sintering temperatures. Images were acquired and analyzed via Digital Image Correlation (DIC). Notch Opening Displacements were used to evaluate the fracture energy at room and high tempartures. For the studied material, a $50^{\circ} \mathrm{C}$ increase in the sintering temperature increased about $30 \%$ the fracture energy of the material, which is also higher at $600{ }^{\circ} \mathrm{C}$ when compared to room temperature measurements.
\end{abstract}

\section{Introduction}

Many high-temperature processes require refractory castables for thermal insulation, from raw material production to final engineering parts [1]. These materials usually consist of coarser aggregates bound by a fine matrix [2], and compositions are being constantly developed to sustain more extreme conditions with maximum lifetime and minimum cost $[3,4]$. Therefore, experiments should be developed accordingly to give trustworthy results, and provide insight into these new microstructures and their properties, allowing applications to be numerically simulated, thereby diminishing experimental trial and error procedures.

These refractories are known to be brittle or quasi-brittle. Experimental setups such as the Wedge Splitting Test (WST) allow stable crack propagation to be achieved even for heterogeneous microstructures [5-9]. Forces are intensified horizontally without substantially increasing the elastic energy stored in the testing frame by using a wedge and cylinders to convert the vertical load into splitting force. This stability is crucial when toughening mechanisms and fracture energy are the subject of investigation [10]. The influence of lateral grooves to guide the crack was investigated [11], and the authors found that they reduced the measured fracture energy since the crack did not necessarily propagate along the weakest path.

For trustworthy identification, it is important that the experiments be performed as closest to the application condition as possible, especially in similar temperature ranges [12]. However, thermomechanical experiments can be laborious, expensive and exhibit several challenges related to thermal insulation, loading setup and extensometry. One robust form of measurement to substitute common extensometers is Digital Image Correlation (DIC) that does not require contact with the specimen and also provides full-field data [13-15], also allowing to analyze local phenomena (e.g., cracks). Recently, DIC was successfully used to study crack propagation in refractories [16-25]. However, when DIC is to be applied at high-temperatures, special care should be taken to handle effects related to heat-haze [26-29], changing emissivities [30] and black body radiation [31-34] (when above $800{ }^{\circ} \mathrm{C}$ ), and pattern preparation [26, 28, 3335].

Different parameters and material formulations were tested in the first reports of high-temperature WST results [10, 36] and highlighted the importance of measuring fracture parameters close to application temperatures. Buchebner et al. [37] discussed how results from WSTs performed at $1000^{\circ} \mathrm{C}, 1250{ }^{\circ} \mathrm{C}$, and $1500^{\circ} \mathrm{C}$ could help to develop industrial products. Brisson et al. [38] tested the addition of andalusite in the refractory composition with WST at $1200{ }^{\circ} \mathrm{C}$ and

*Corresponding author

@r.vargas_m@ppgcem.ufscar.br (R. Vargas)

ORCID(s): 0000-0002-1711-9804 (R. Vargas); 0000-0001-5553-0066 (F. Hild); 0000-0002-9286-9912 (R.B. Canto) 
$1400{ }^{\circ} \mathrm{C}$. Very recently, silica refractories were tested with WSTs up to $1100{ }^{\circ} \mathrm{C}$ [39] and $\mathrm{MgO}-\mathrm{C}$ refractories up to $1470{ }^{\circ} \mathrm{C}[40]$.

It is worth noting that the above cited references on WSTs conducted at high-temperatures did not use full-field measurements. A first case in which the Crack Mouth Opening Displacement (CMOD) was measured from images of $\mathrm{MgO}-\mathrm{C}$ samples in WSTs up to $1500{ }^{\circ} \mathrm{C}$ was reported by Brochen et al. [41]. Moreover, to the authors' best knowledge, only one work reported WSTs analyzed with full-field measurements via DIC at a temperature of $1200{ }^{\circ} \mathrm{C}$ ) [42] on a commercial refractory for the calibration of a cohesive zone model.

Pan et al. [43] studied through WSTs the influence of different sintering temperatures on the fracture energy evaluated at room temperature. In this work, WSTs were performed up to $600{ }^{\circ} \mathrm{C}$ with DIC measurements on samples with two different sintering temperatures $\left(1400{ }^{\circ} \mathrm{C}\right.$ and $\left.1450{ }^{\circ} \mathrm{C}\right)$, with and without lateral grooves to guide the crack. The fracture energy was extracted from notch opening displacement measurements (via DIC) for the five investigated tests. First, the material is described, followed by the experiment description. Results related to uncertainty quantification, crack propagation, and fracture energy are then discussed.

\section{Material and Tests}

\subsection{Studied Material}

The material studied herein consists of an alumina matrix with mullite-zirconia aggregates kindly provided by Indústrias Brasileiras de Artigos Refratários (IBAR), Poá, Brazil. This material was chosen due to its technological importance, namely, the presence of zirconia leads to interesting high-temperature transformation mechanisms [44, 45], and also for presenting good contrast for tomographic analyses [46]. The global composition remains mainly in the $\mathrm{Al}_{2} \mathrm{O}_{3}-\mathrm{ZrO}_{2}-\mathrm{SiO}_{2}$ ternary diagram, with the \%wt of each of the three oxides being $86.0,8.0$ and 4.0, respectively.

Two sintering temperatures were considered, namely, $1400^{\circ} \mathrm{C}$ and $1450^{\circ} \mathrm{C}$. These processing temperatures are not believed to greatly change the fused aggregate microstructure since below $1500^{\circ} \mathrm{C}$ there is hardly any presence of liquid phases for these compositions [47]. Fractographies focused on aggregates after sintering are shown in Figure 1.

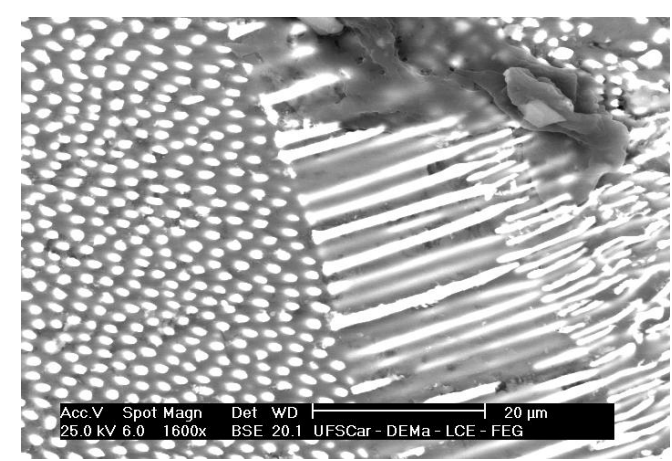

(a)

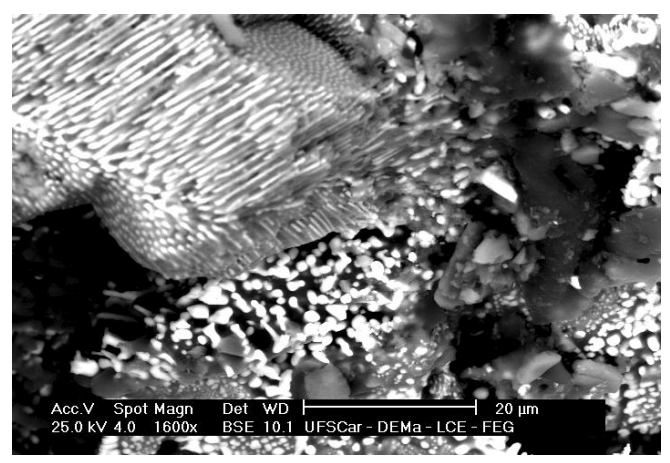

(c)

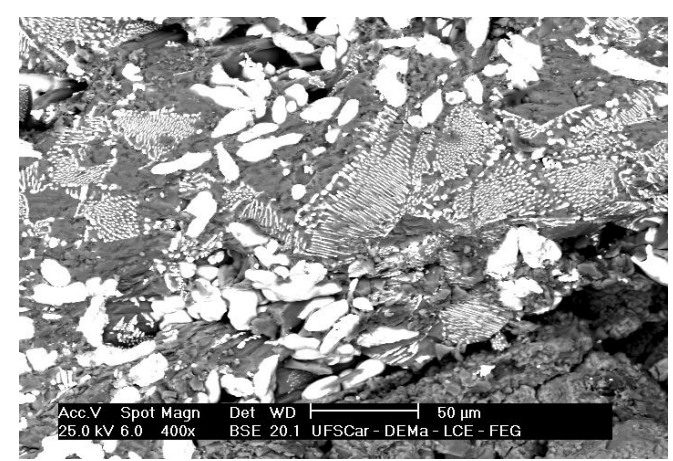

(b)

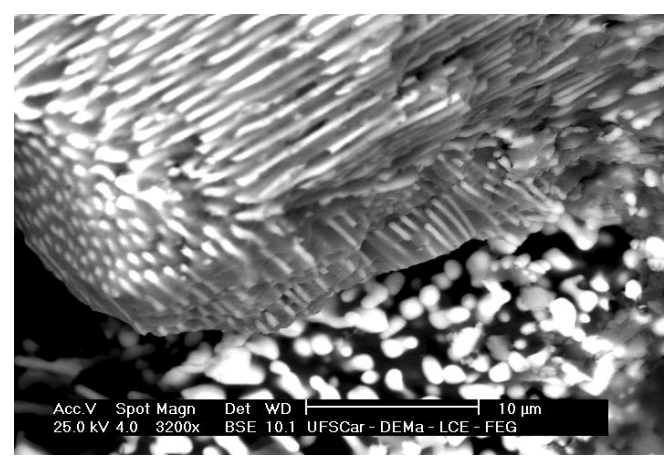

(d)

Figure 1: SEM images of the aggregates for samples sintered at (a-b) $1400{ }^{\circ} \mathrm{C}$ and (c-d) $1450{ }^{\circ} \mathrm{C}$ 
Overall, primary $\mathrm{ZrO}_{2}$ particles are round and white, and the following eutetic mullite-zirconia formation, with fine $\mathrm{ZrO}_{2}$ cylinders involved in a mullite matrix. These eutetic formations hinder crack propagation [48] since a lot of energy is needed to traverse these aggregates, and thus the crack usually gets around them. The influence of the two sintering temperatures on the fracture energy is discussed in the following sections.

A tomographic scan was performed for one cube of castable. Figure 2(a) shows a 3D rendering of the material microstructure, and Figures 2(b-d) corresponding central sections in three orthogonal directions (i.e., orthoslices). The alumina matrix (gray hues) is seen with mullite-zirconia aggregates (light hues, diameters ranging between 0.5 and $2.5 \mathrm{~mm}$ ) finely dispersed within the volume, besides some porosity (darker zones). The darker zones are pores, even though not intentionally added, that provide additional contrast for Digital Volume Correlation analyses [46].

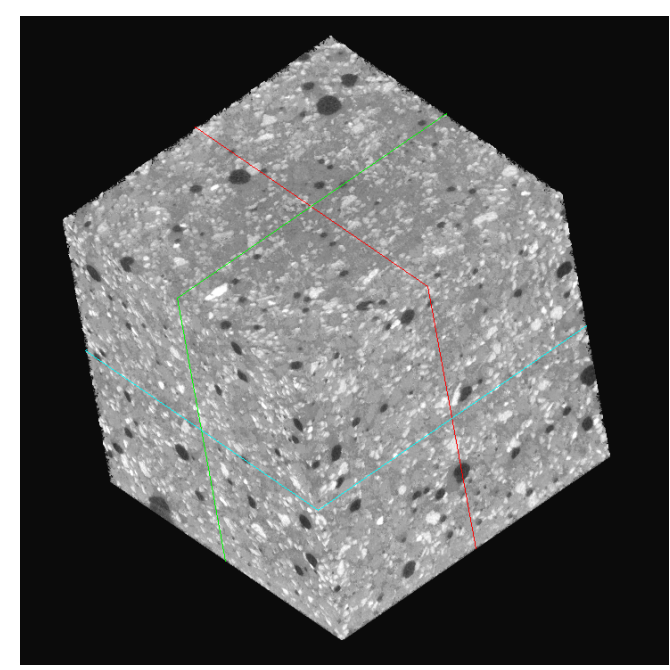

(a)

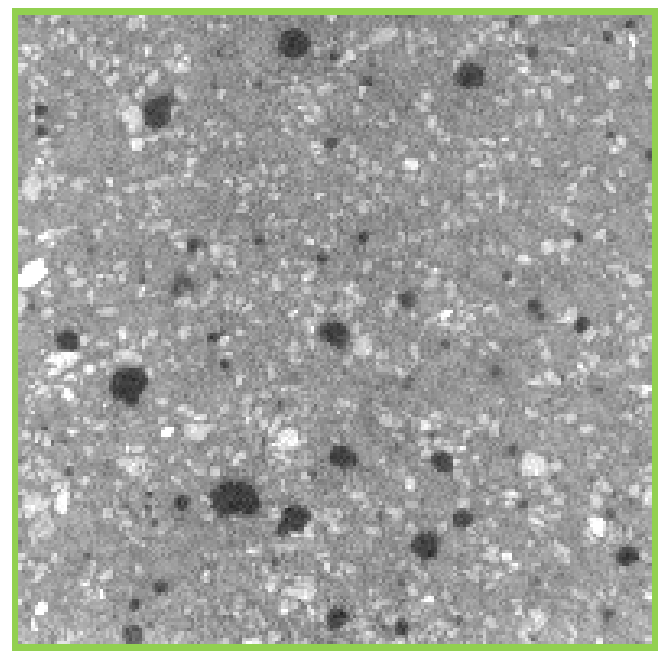

(c)

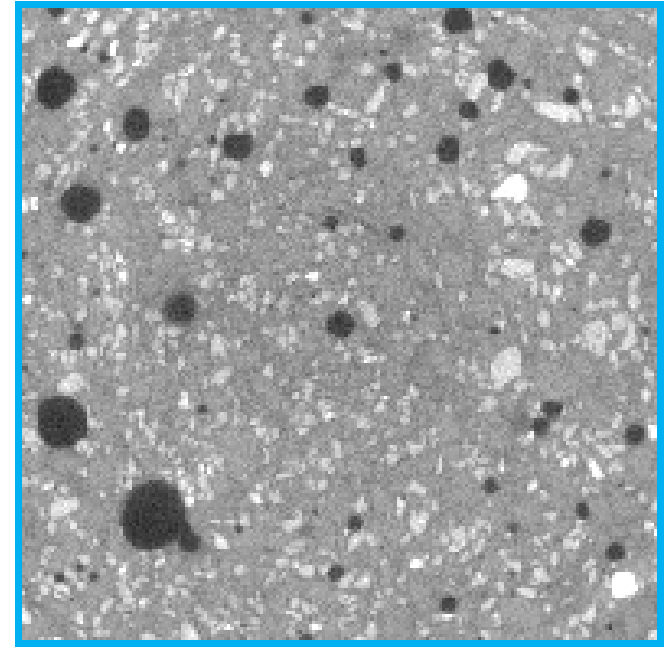

(b)

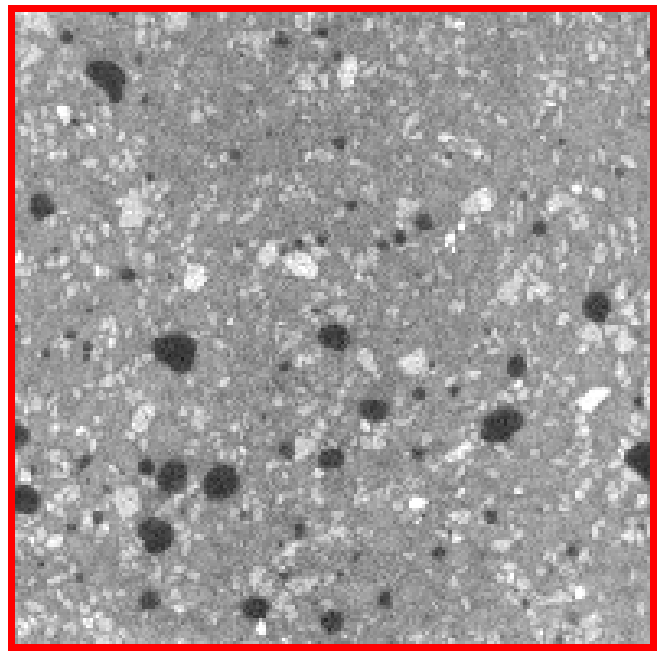

(d)

Figure 2: (a) 3D rendering of a cube (volume: $45 \times 45 \times 45 \mathrm{~mm}^{3}$ ) of the studied material . (b-d) Orthoslices corresponding to the sections shown in subfigure (a)

\subsection{Performed Tests}

Wedge splitting tests were performed at room temperature and $600^{\circ} \mathrm{C}$ (Figure 3). Such tests are commonly used for the measurement of fracture energy of brittle materials [5-7]. A total of five samples was tested. Three of these samples were fired at $1450^{\circ} \mathrm{C}$ (two with lateral grooves and one without), and the other two were fired at $1400^{\circ} \mathrm{C}$ (one with 
lateral grooves and one without). They are designated as "S-firing temperature-groove indication," and sequentially as MZ1, MZ2 and so on (MZ after mullite-zirconia aggregates). For example, sample S1450G was fired at $1450^{\circ} \mathrm{C}$ and had lateral grooves (for S1450, no groove was present). Only the first test (MZ1-S1450G) was performed at room temperature for comparison purposes.

The wedge splitting setup within the furnace is shown in Figure 3(a). In the present case, the loading parts (wedge, two cylinders, and two plates) were made of alumina to sustain increased temperatures (Figure 3(b)), following the guidelines of Ref. [9]. The sample geometry is identical to that utilized in Refs. [17, 22, 25], and consists of a $100 \times$ $100 \times 75 \mathrm{~mm}^{3}$ (width $\times$ height $\times$ thickness) rectangular cuboid molded with the notch.

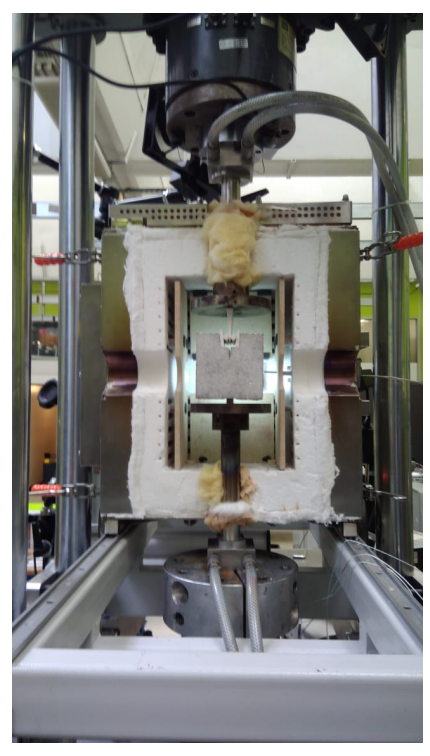

(a)

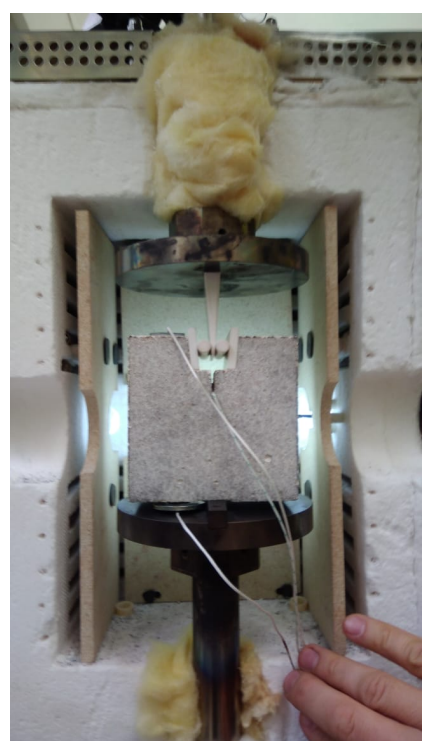

(b)

Figure 3: Furnace, coupled to the testing machine, open to show the setup. General view (a) and more detailed image of the wedge splitting setup (b)

The raw output from the testing machine (i.e., applied force as a function of actuator displacement) is shown for the five tests in Figure 4. All tests exhibited stable crack propagation (i.e., with no abrupt post-peak failure). At $600{ }^{\circ} \mathrm{C}$, an increase in displacement levels is observed with similar load levels in comparison to the room temperature test. The cases with no groove show higher peak loads since more material is sustaining the forces. 


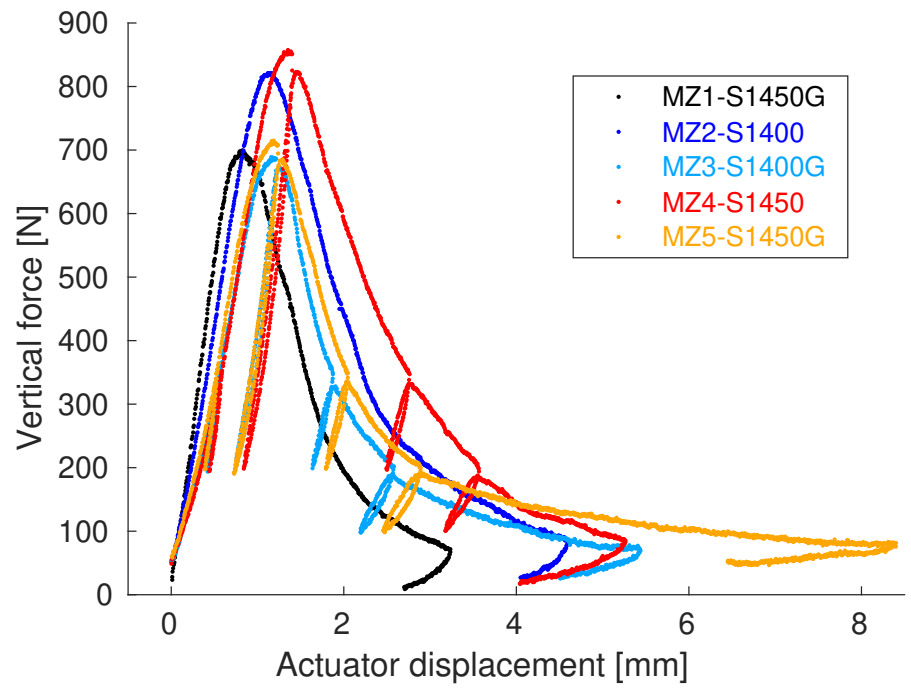

Figure 4: Load vs. displacement (raw data from the testing machine) of the five tests

A total of 7,281 images were acquired for these 5 tests. An additional 100 pictures were acquired at the testing temperature, just prior to the beginning of loading for uncertainty quantification. The hardware parameters of the optical setup are reported in Table 1. Care was taken to ensure that both lateral edges of the samples could be seen in the reference images (see Figure 5) to convert pixels into metric units (i.e., image scale).

Table 1

DIC hardware parameters

\begin{tabular}{|l|l|}
\hline \hline Camera & Canon 70D \\
\hline Definition & $5472 \times 3648 \mathrm{px}$ \\
Gray Levels amplitude & $8 \mathrm{bits}$ \\
Lens & Canon Macro 100 \\
Field of view & $104 \times 69 \mathrm{~mm}^{2}$ \\
Image scale & $19 \mu \mathrm{m} / \mathrm{px}$ \\
Stand-off distance & $50 \mathrm{~cm}$ \\
Image acquisition rate & $0.1 \mathrm{fps}$ \\
Patterning technique & sprayed paints \\
Pattern size & $5 \mathrm{px}($ MZ1-S1450G, MZ2-S1400, MZ3-S1400G) \\
& $12 \mathrm{px}($ MZ4-S1450, MZ5-S1450G) \\
\hline \hline
\end{tabular}

\section{Uncertainty Quantification}

To illustrate the challenges associated with high temperature experiments [26-28, 31-34], uncertainty quantification was performed for all five tests. One hundred pictures were acquired before each test and registered via T3-DIC [49] over the regions of interest shown in Figure 5. The DIC analysis parameters are gathered in Table 2. It is worth noting that the whole sample surfaces could not be imaged because the furnace window was not high enough. It was decided to focus on the crack propagation path. For the high temperature tests (Figure 5(b-e)), the black trace on the left side of images is the shadow of the front thermocouple, which was excluded from DIC analyses. 


\section{Table 2}

DIC analysis parameters

\begin{tabular}{|l|l|}
\hline \hline DIC software & Correli 3.0 [50] \\
Image filtering & none \\
Element length & $80 \mathrm{px}$ \\
Shape functions & linear (T3) \\
Mesh & see Figure 5 \\
Matching criterion & penalized sum of squared differences \\
Interpolant & cubic \\
Displacement noise-floor & $0.02 \mathrm{px}$ (Table 3) \\
\hline \hline
\end{tabular}

Further, to compute crack opening histories, optical gauges were also considered $(\approx 7.6 \mathrm{~mm}$ yellow squares in 106 Figure 5). In the present case, they were placed around the notch root and thus the notch opening displacement was $\mathbf{1 0 7}$ measured.

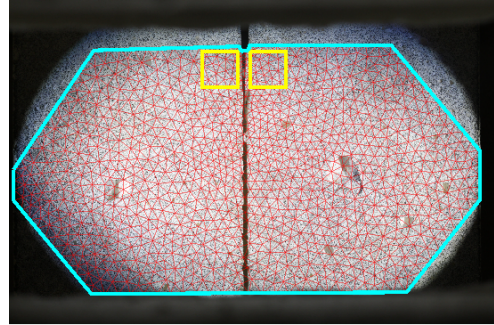

(a) MZ1-S1450G

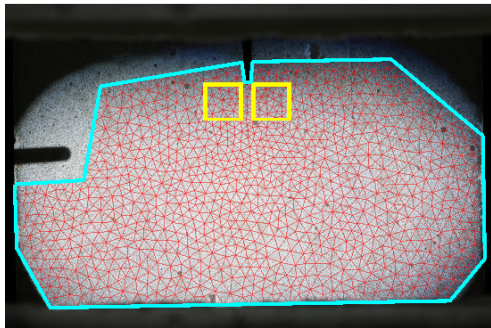

(b) MZ2-S1400

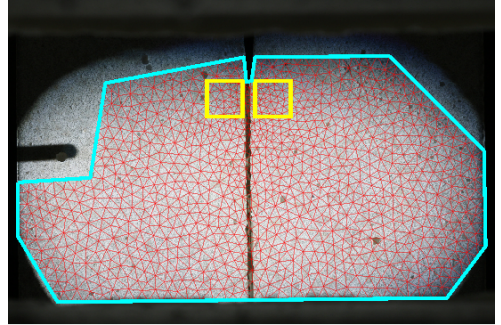

(c) MZ3-S1400G

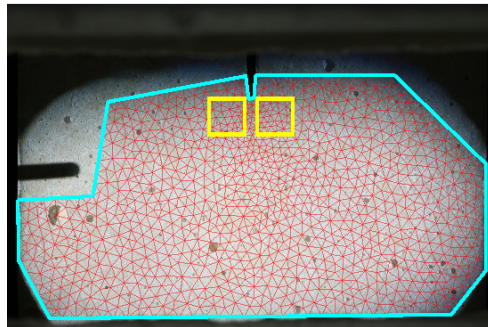

(d) MZ4-S1450

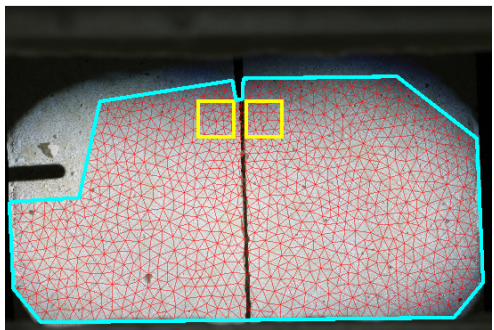

(e) MZ5-S1450G

Figure 5: DIC meshes over reference images of the five tests. The cyan contours are the regions of interest for DIC analyses. The yellow boxes depict the area used for crack opening displacement (COD) calculations

For each measured degree of freedom, the temporal variance was computed. For each direction, a displacement map was obtained. Figure 6 shows the standard displacement uncertainty maps for the experiment conducted at room temperature. It is worth noting that all uncertainty maps are shown with the color bars centered about their mean, plus and minus one standard deviation. The fields are rather uniform and as one moves to the external edges, the levels increase. The two spots seen are related to bigger pores in the imaged surface, as seen in Figure 5(a). 


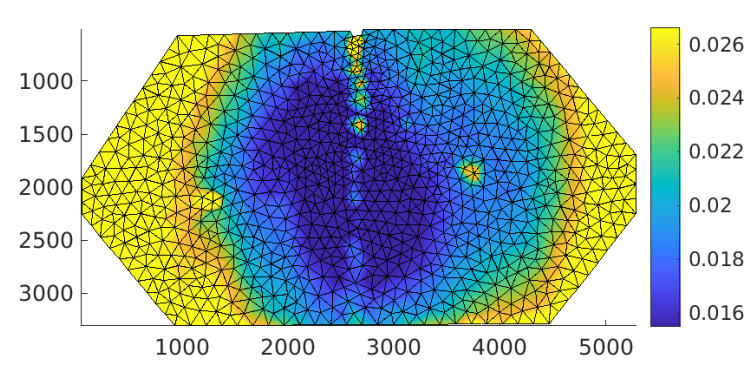

(a)

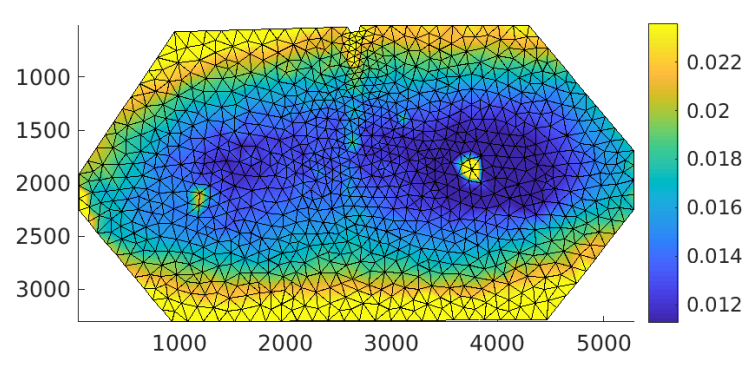

(b)

Figure 6: Standard displacement field (expressed in px) related to each node for MZ1-S1450G (performed at room temperature) in (a) horizontal and (b) vertical directions

From the variance maps, their average level was computed for each direction and its square root is referred to as standard displacement uncertainty. For the room temperature test, the standard displacement uncertainties are of the order of 2 cpx (Table 3), which is low and in line with noise floor levels generally associated with DIC [51].

\section{Table 3}

Standard displacement uncertainty for each test in the horizontal and vertical directions

\begin{tabular}{|c|c|c|c|}
\hline Test & Testing temperature & $\sigma_{x}[\mathrm{cpx}]$ & $\sigma_{y}[\mathrm{cpx}]$ \\
\hline \hline MZ1-S1450G & room temperature & 2 & 2 \\
\hline \hline MZ2-S1400 & $600^{\circ} \mathrm{C}$ & 21 & 12 \\
\hline MZ3-S1400G & $600^{\circ} \mathrm{C}$ & 19 & 11 \\
\hline MZ4-S1450 & $600^{\circ} \mathrm{C}$ & 18 & 9 \\
\hline MZ5-S1450G & $600^{\circ} \mathrm{C}$ & 21 & 14 \\
\hline
\end{tabular}

The same analyses were run for the four high temperature tests. In that case, the images were acquired once the $\mathbf{1 1 7}$ target temperature was reached. Figure 7 shows the standard displacement uncertainty maps. Spatial fluctuations are 118 observed with high levels in comparison with room temperature fields (Figure 6). The standard displacement uncer- 119 tainties are between 5 times and 10 times higher in comparison to room temperature levels (Table 3). These significant $\mathbf{1 2 0}$ differences are due to heat haze effects [26-29]. Interestingly, the uncertainty associated with the horizontal displace- $\mathbf{1 2 1}$ ments is consistently higher and heat haze effects are also more prominent on the corresponding fields (Figure 7). It is assumed that it is related to the inner flow of air that dominantly occurs in the horizontal direction. 


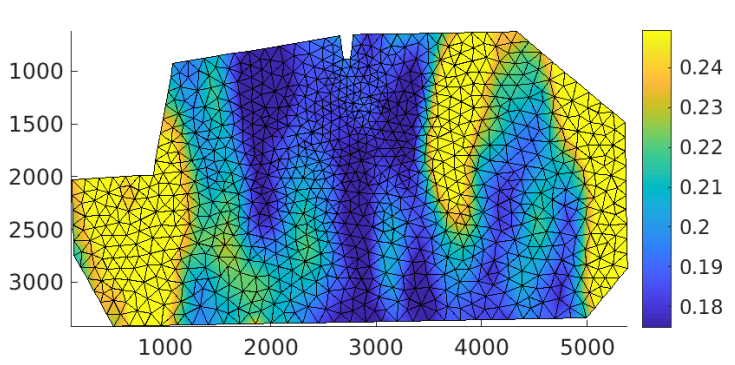

(a)

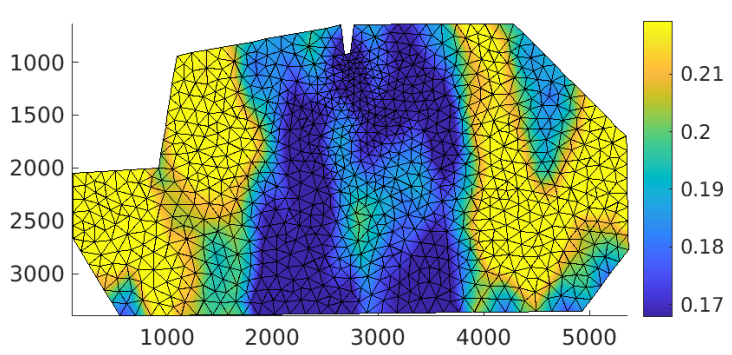

(c)

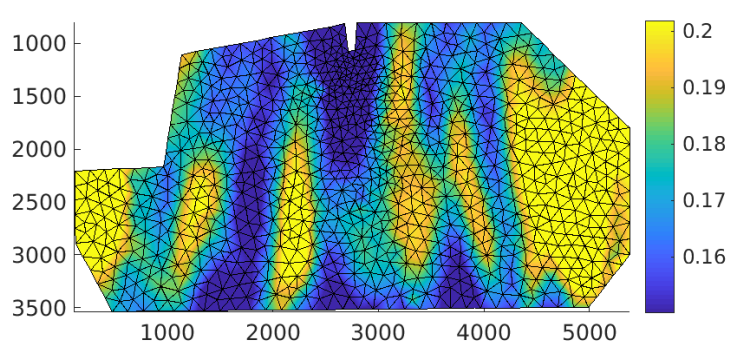

(e)

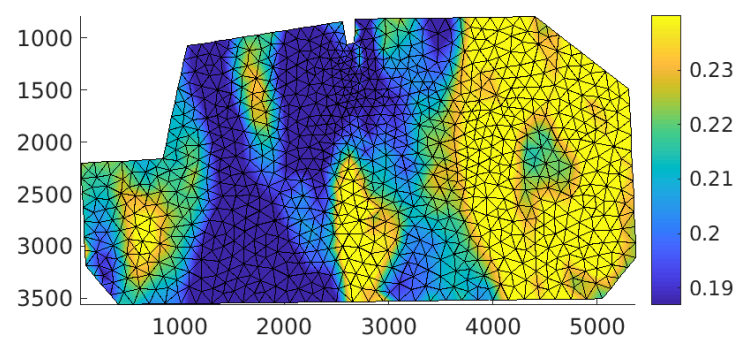

(g)

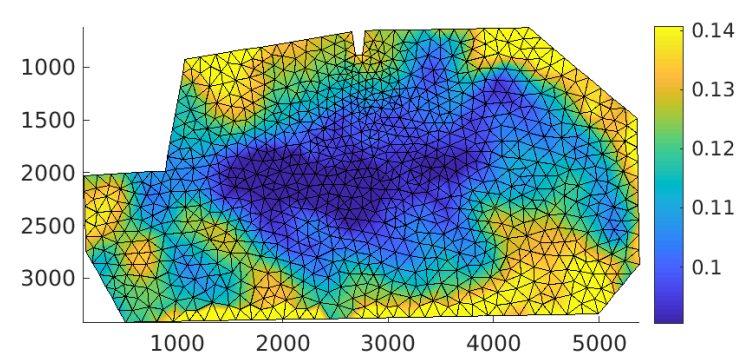

(b)

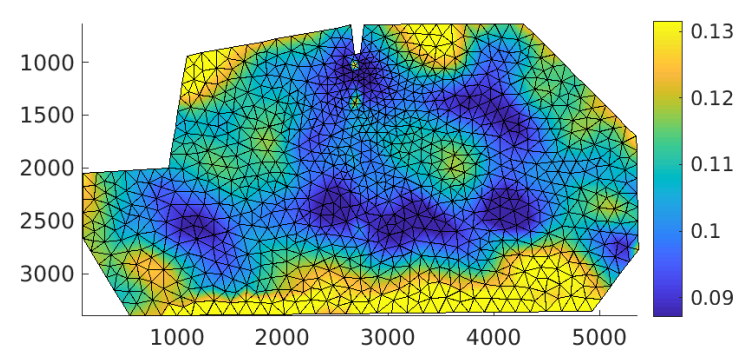

(d)

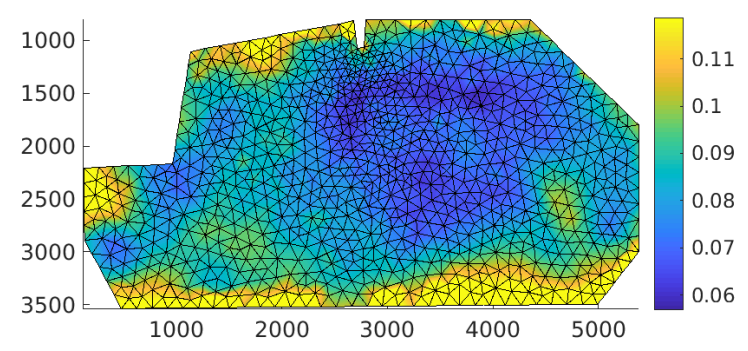

(f)

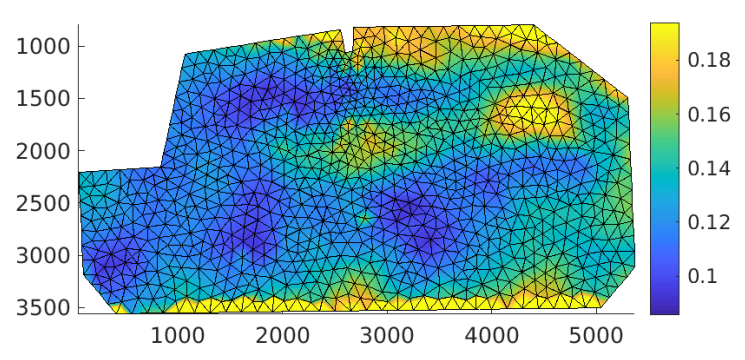

(h)

Figure 7: Standard displacement uncertainty field (expressed in px) related to each node for MZ2-S1400 (a,b), MZ3-S1400G $(\mathrm{c}, \mathrm{d})$, MZ4-S1450 (e,f), and MZ5-S1400G $(\mathrm{g}, \mathrm{h})$ in the horizontal (left column) and vertical (right column) directions

Further evaluations were performed when computing the mean displacement of the optical gauges from which $\mathbf{1 2 4}$ displacement differences then correspond to notch opening displacements (NODs). For each test, their standard un- $\mathbf{1 2 5}$ certainties are reported in Table 4. Their levels are close to those associated with the full field (Table 3). 


\section{Table 4}

Standard NOD uncertainty for each test in the horizontal and vertical directions

\begin{tabular}{|c|c|c|c|}
\hline Test & Testing temperature & $\sigma_{x}[\mathrm{cpx}]$ & $\sigma_{y}[\mathrm{cpx}]$ \\
\hline \hline MZ1-S1450G & room temperature & 1.5 & 0.8 \\
\hline \hline MZ2-S1400 & $600^{\circ} \mathrm{C}$ & 20 & 9 \\
\hline MZ3-S1400G & $600^{\circ} \mathrm{C}$ & 23 & 10 \\
\hline MZ4-S1450 & $600^{\circ} \mathrm{C}$ & 22 & 6 \\
\hline MZ5-S1450G & $600^{\circ} \mathrm{C}$ & 25 & 10 \\
\hline \multicolumn{4}{|c|}{}
\end{tabular}

The maximum eigen strain $\epsilon_{1}$ fields are also discussed hereafter to visualize the crack path [52]. The correspond- $\mathbf{1 2 7}$ ing standard uncertainty fields are shown in Figure 8. Overall, the same trend of the room temperature test presenting $\mathbf{1 2 8}$ smaller noise remains, but here a higher uncertainty region around the vertical grooves in the middle of the samples $\mathbf{1 2 9}$ (Figure 8(a,c,e)), which is due to the absence of speckle pattern and more importantly shadows induced by the lighting 130 conditions. In the $600^{\circ} \mathrm{C}$ temperature cases (Figure 8(b-e)), fluctuations related to heat haze effects are also distin- 131 guished. The corresponding standard strain uncertainties are gathered in Table 5. Their levels in high-temperature

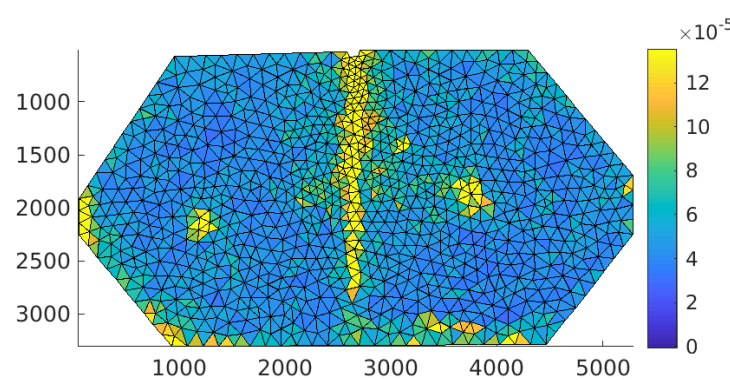

(a)

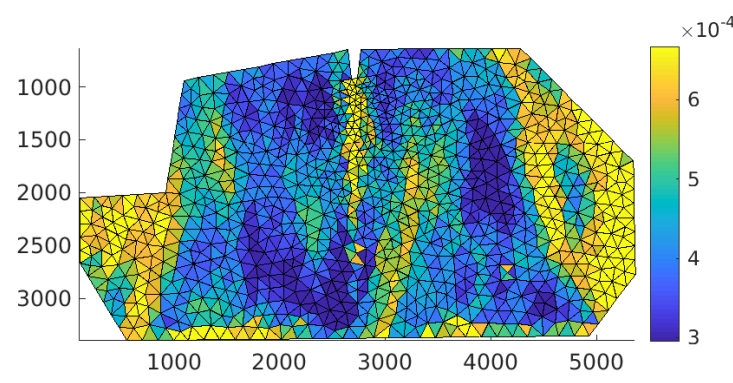

(c)

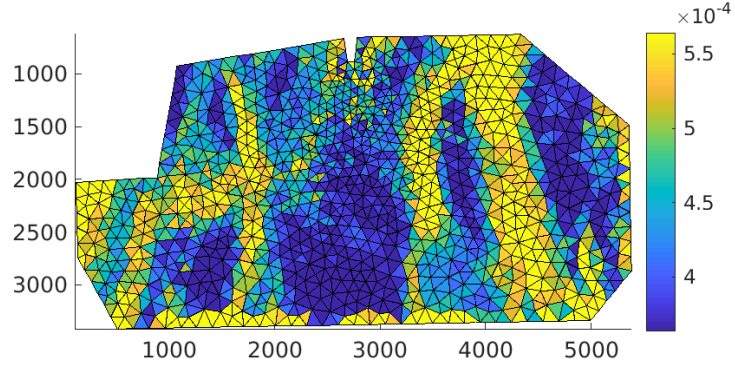

(b)

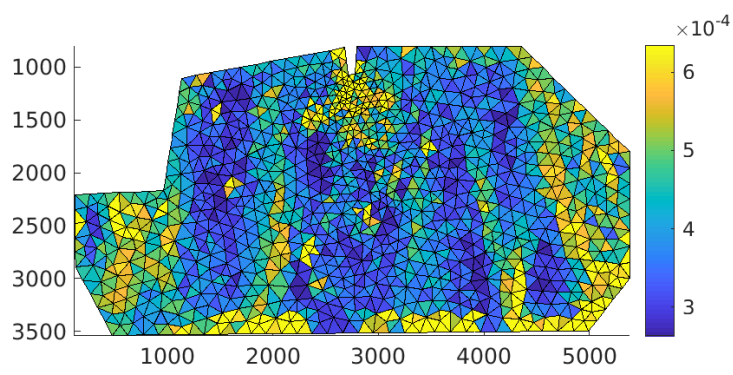

(d)

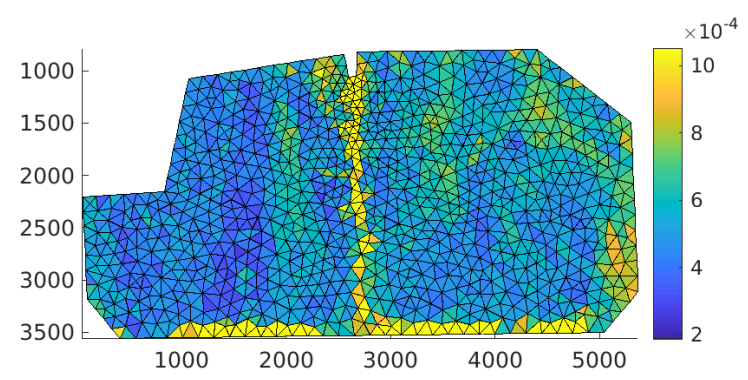

(e)

Figure 8: Standard $\epsilon_{1}$ uncertainty fields related to each element for tests (a) MZ1-S1450G, (b) MZ2-S1400, (c) MZ3S1400G, (d) MZ4-S1450, and (e) MZ5-S1450G 
tests are one order of magnitude higher when compared to the room temperature test as expected from the standard $\mathbf{1 3 3}$ displacement uncertainties (Table 3).

Table 5

Standard strain $\varepsilon_{1}$ uncertainty for each test

\begin{tabular}{|c|c|c|}
\hline Test & Testing temperature & $\sigma_{\varepsilon_{1}}[-]$ \\
\hline \hline MZ1-S1450G & room temperature & $6.7 \times 10^{-5}$ \\
\hline \hline MZ2-S1400 & $600^{\circ} \mathrm{C}$ & $4.6 \times 10^{-4}$ \\
\hline MZ3-S1400G & $600^{\circ} \mathrm{C}$ & $4.8 \times 10^{-4}$ \\
\hline MZ4-S1450 & $600^{\circ} \mathrm{C}$ & $4.5 \times 10^{-4}$ \\
\hline MZ5-S1450G & $600^{\circ} \mathrm{C}$ & $6.2 \times 10^{-4}$ \\
\hline
\end{tabular}

\section{Crack propagation Path}

The crack propagation path is reported thanks to the maximum eigen strain fields. Further, for the samples with 136 no groove, tomographic analyses were conducted to reveal the crack path in the bulk.

\subsection{Strain Fields}

The strain fields for the image acquired at the peak loads (Figure 4), and also 50\% of the peak load (in the post- 139 peak regime) are shown in Figure 9. Globally, the crack propagated vertically in all cases even for samples MZ2-S1400 140 (Figure 9(c-d)) and MZ4-S1450 (Figure 9(g-h)) with no groove. Crack branching is seen in Figure 9(g-h), which will be discussed in the following section. Although it was shown that the groove region had increased uncertainty levels (see Figure 8), it does not appear much in the MZ1-S1450G result (Figure 9(a-b)) performed at room temperature but was more present in the higher temperature tests (i.e., for MZ3-S1400G in Figure 9(c) and MZ5-S1450G in Figure 9(i)). 


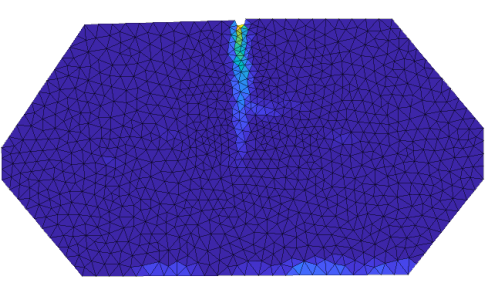

(a)

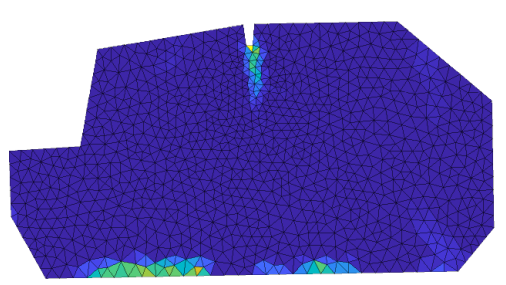

(c)

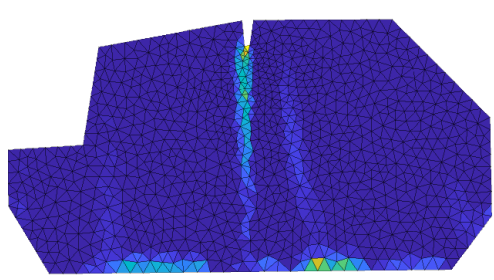

(e)

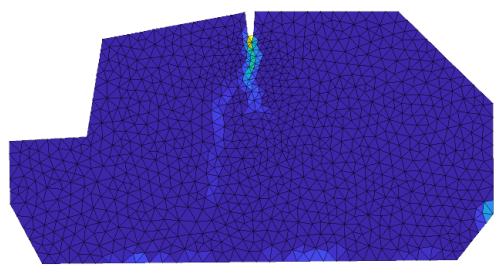

$(\mathrm{g})$

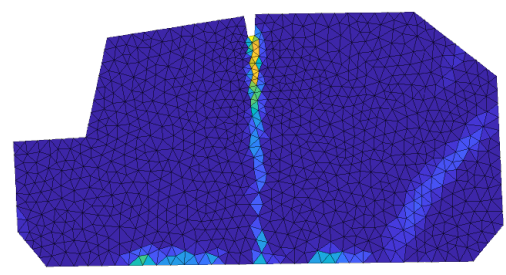

(i)
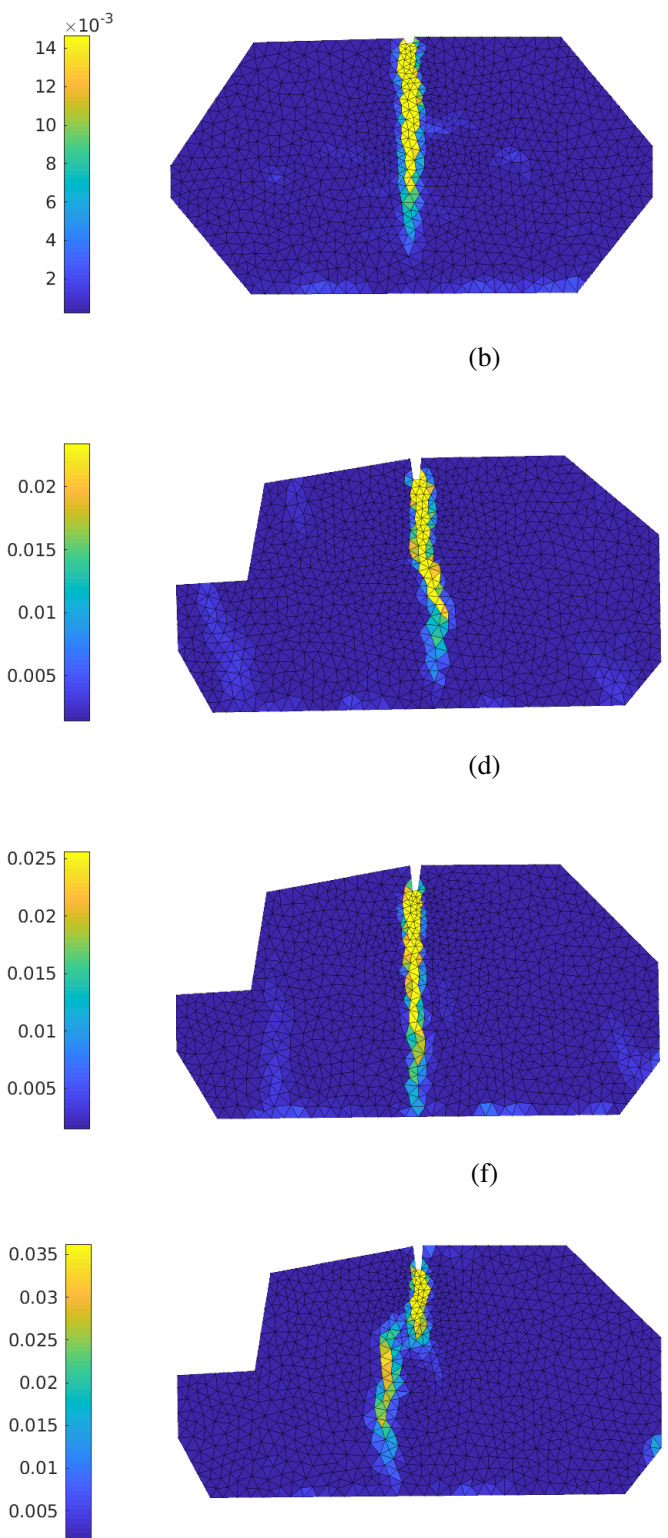

(h)
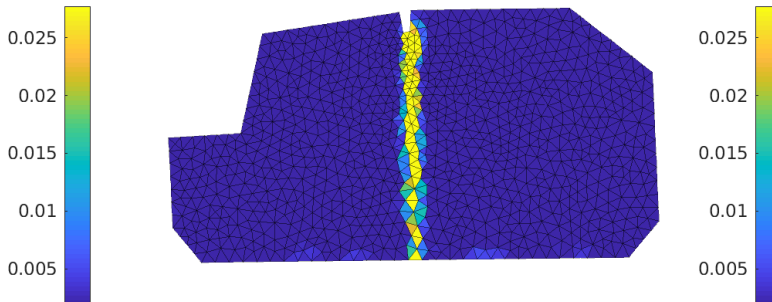

(j)

Figure 9: Maximum eigen strain maps for tests (a-b) MZ1-S1450G, (c-d) MZ2-S1400, (e-f) MZ3-S1400G, (g-h) MZ4S1450, and (i-j) MZ5-S1450G, for the peak load image (left column) and for $50 \%$ of peak load after peak (right column) for every test 


\subsection{Post-mortem Tomographic Analyses}

To further analyze the crack path and crack branching in the samples with no groove, the maximum principal strain $\mathbf{1 4 6}$ fields are shown for the same frame shown at the right in Figure 9 but now with a finer mesh (i.e., 9 px elements) and $\mathbf{1 4 7}$ closer to the crack path. Figure 10 shows the maximum principal strain field for 50\% of peak load (post-peak regime) 148 where a bifurcation was observed in Figure 9(h) for the MZ4-S1450 sample (i.e., bright red curve in Figure 4). The absence of groove explains why multiple branching may occur [11].

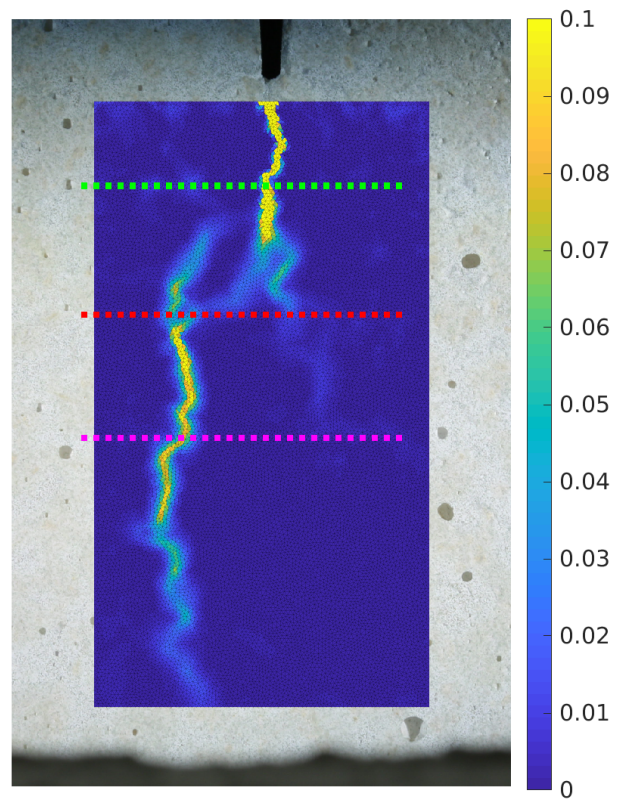

Figure 10: Maximum principal strain fields for $50 \%$ of maximum load (post-peak regime) for the MZ4-S1450 sample. The red dashed line depicts the section of the tomographic scan analyzed in Figure 11. The three horizontal segments depict the width and location of the sections shown in Figure 12

Both samples with no groove were scanned after the end of the test in the tomograph of LMT (NSI, XCT 50+) to 151 analyze whether the previous surface cracks were visible. For the MZ4-S1450 test, one interesting result is shown in $\mathbf{1 5 2}$ Figure 11. The bulk data from the reconstructed volume show that the bifurcation seen in the strain fields obtained $\mathbf{1 5 3}$ from 2D-DIC (Figure 10) occurred only close to the surface, while a single macrocrack is observed in the bulk of the $\mathbf{1 5 4}$ sample. 


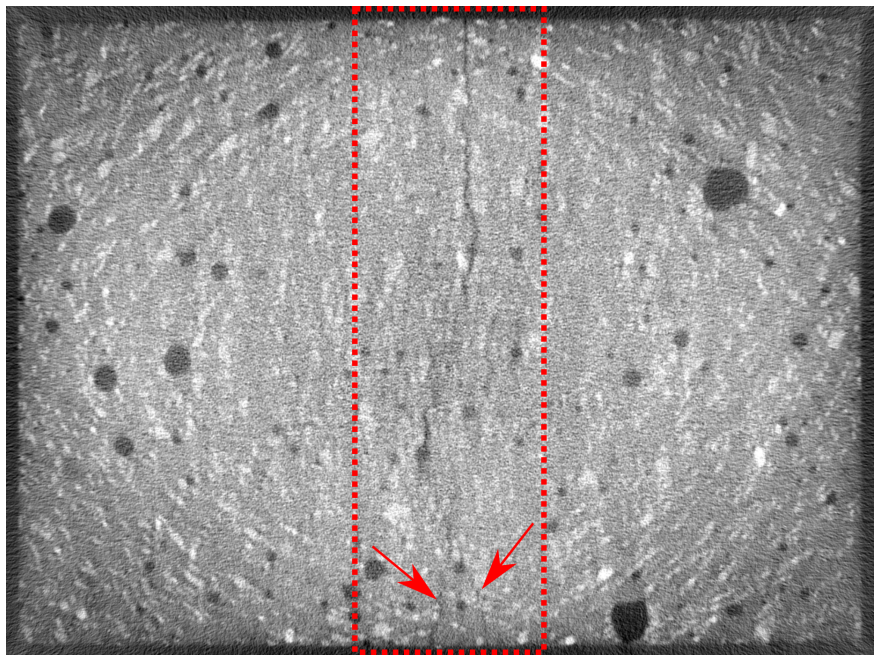

(a)

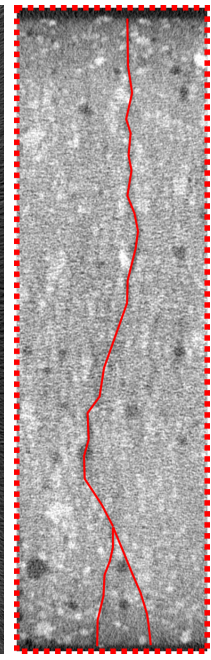

(b)

Figure 11: (a) Slice of the reconstructed volume of the MZ4-S1450 sample imaged post-mortem via tomography (see dashed red line in Figure 10). One single macrocrack is observed in the bulk, which branched close to the sample surface (red arrows). (b) Highlighted crack

If other heights are analyzed the same way (Figure 12), the farther from the previously shown slice, the straighter the macrocrack appears. These results highlight the importance of bulk measurements, and especially how one may be misled by surface results alone, namely, there is essentially one dominant crack that was created in this sample with no groove.

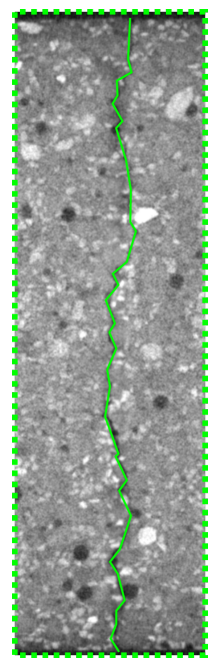

(a)

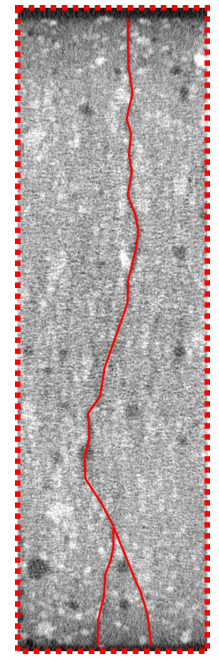

(b)

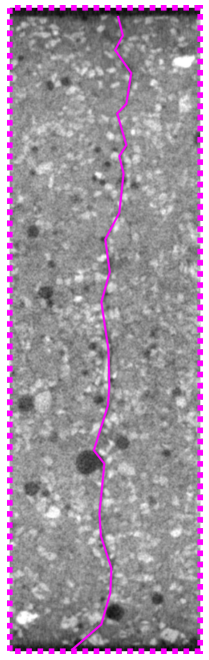

(c)

Figure 12: Three horizontal slices of the MZ4-S1450 sample (see dashed lines in Figure 10)(a) closer to the notch, (b) in the branching region, and (c) below the latter. The surface shown in Figure 10 corresponds to the bottom line of the slices

To compare with the previous result, a similar analysis was performed for the MZ2-S1400 sample (post-peak at $\mathbf{1 6 0}$ $50 \%$ of maximum load, similar mesh size, and zoomed region). In that case, no branching was visible in Figure 9(d), 161 which is confirmed with the refined DIC analysis presented in Figure 13. Even without groove, the cracks propagated 162 very closely to the central plane of the specimen. 


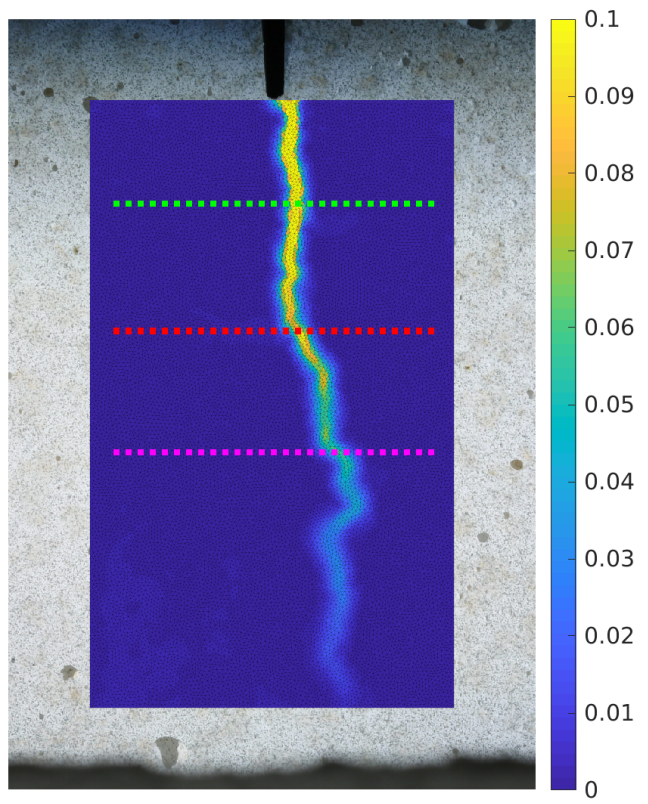

Figure 13: Maximum principal strain fields for $50 \%$ of maximum load (post-peak) for the MZ2-S1400 sample. The dashed red line depicts the section of the tomographic scan analyzed in Figure 14. The three horizontal segments depict the width and location of the sections shown in Figure 15

Specimen MZ2-S1400 was also scanned and one section of the volume is shown in Figure 14(a), with the high- $\mathbf{1 6 4}$ lighted straight crack throughout the thickness in Figure 14(b).

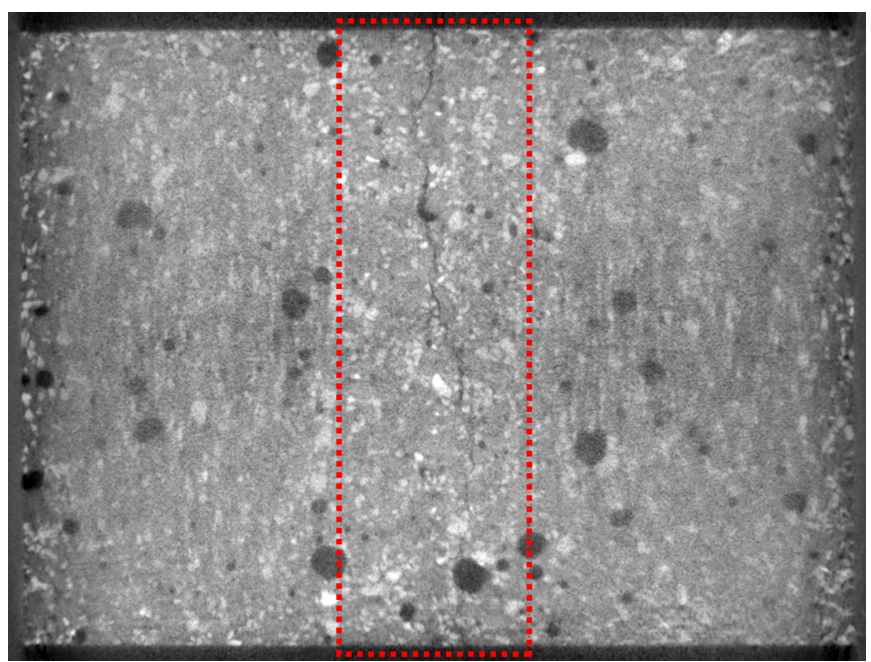

(a)

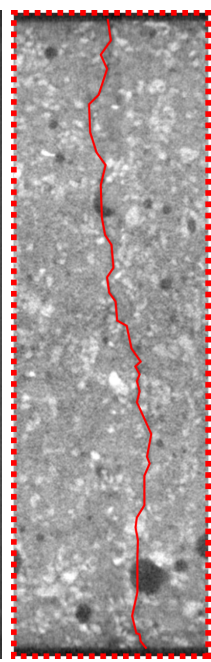

(b)

Figure 14: (a) Slice of the reconstructed volume of the MZ2-S1400 sample imaged post-mortem via tomography. One single macrocrack is observed in the bulk. (b) Highlighted crack

Similar profiles are obtained if different heights are analyzed as shown in Figure 15. Even though a curved crack $\mathbf{1 6 6}$ appeared in the photographed face, in the other side (inside the oven) the crack propagated even closer to the sample $\mathbf{1 6 7}$ central plane. 


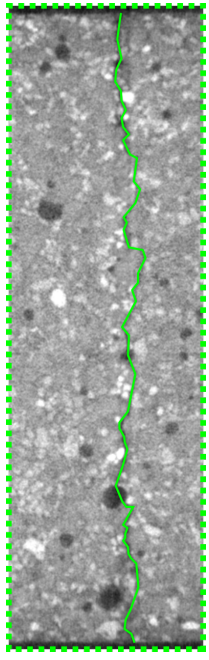

(a)

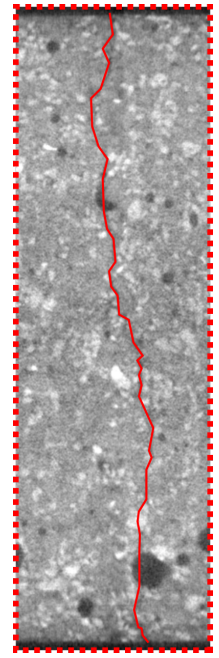

(b)

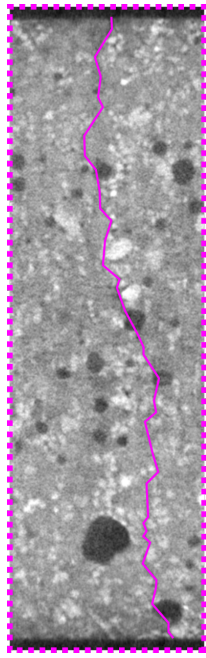

(c)

Figure 15: Three horizontal slices of the MZ4-S1450 sample (see dashed lines in Figure 10) (a) closer to the notch, (b) in the branching region, and (c) below the latter. The surface shown in Figure 13 corresponds to the bottom line of the slices

These post-mortem tomographic results highlight the importance of volume data, and reinforce the hypothesis of 169 one single macrocrack propagating in the central plane.

\section{Fracture Energies}

The main purpose of the optical gauges was to measure the Notch Opening Displacement (NOD) history for the five tests (Figure 16(a)) as a function of the (horizontal) splitting force. The overall trends are identical to those observed on the applied load vs. actuator displacement (Figure 16(b)). The NODs reported in Figure 16(a) are considerably noisier at higher temperature when compared to the room temperature test. This trend was expected since the corresponding measurement uncertainties were tenfold higher than those at room temperature (Table 4).

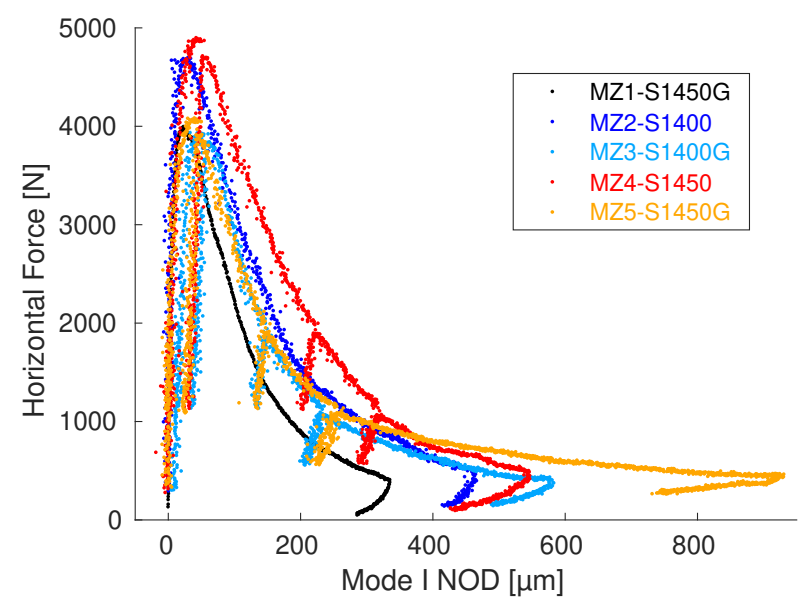

(a)

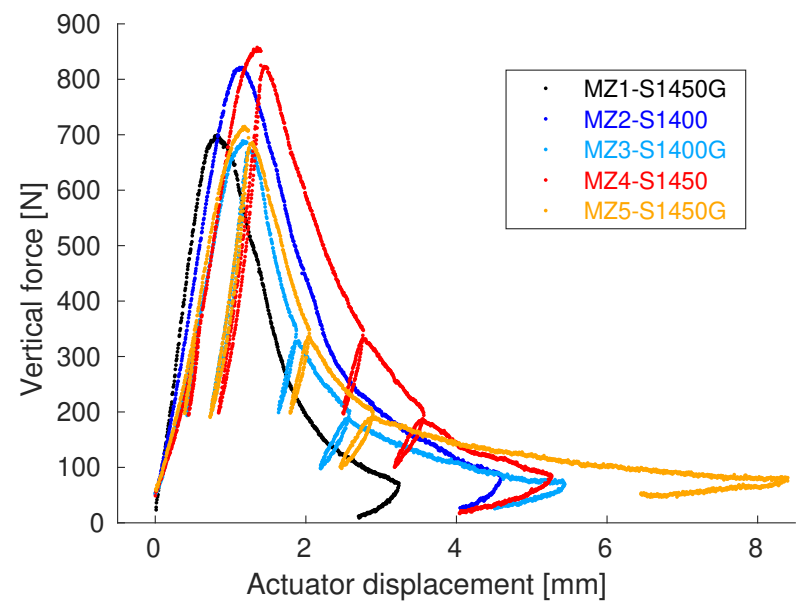

(b)

Figure 16: Loading curves with results (a) converted to horizontal forces coupled with DIC measurements, and (b) directly obtained from testing machine data 
It is worth noting that to compute the work of fracture based on the splitting (horizontal) load, the displacements $\mathbf{1 7 7}$ are needed at their application point onto the sample surface (i.e., the CMOD is needed). In the present case, because $\mathbf{1 7 8}$ of the limited window dimensions of the furnace, the whole surface of the tested samples was not visible (Figure 5) 179 and NODs were measured instead. Consequently, extrapolations have to be proposed to evaluate the CMOD.

\subsection{Evaluating CMOD from NOD measurements}

A virtual experiment was computed with the commercial finite element code Abaqus. The geometry (considering symmetry) is shown in Figure 17, where horizontal forces were applied on the nodes depicted by blue circles. Horizontal displacements were blocked for the nodes with red circles, and were detached one by one to have a total of 32 propagation steps for the coarser mesh, and 120 steps for the finer one with the same force applied but different ligament sizes in the cracked region. The remaining ligament in the propagation region of the final step is about $4 \mathrm{~mm}$. The Young's modulus was equal to $60 \mathrm{GPa}$ and the Poisson's ratio was 0.2. A plane strain assumption with $75 \mathrm{~mm}$ thickness was made. The present analyses are considered sufficient for first order extrapolations. Additional studies are required to fully address this particular issue since initiation was not addressed herein. They lie beyond the scope of the present paper.

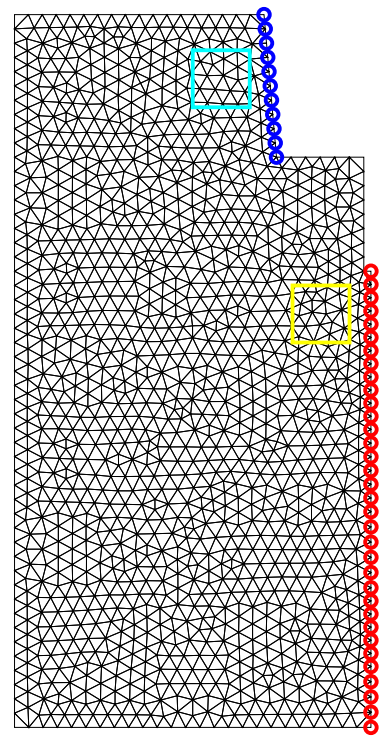

(a)

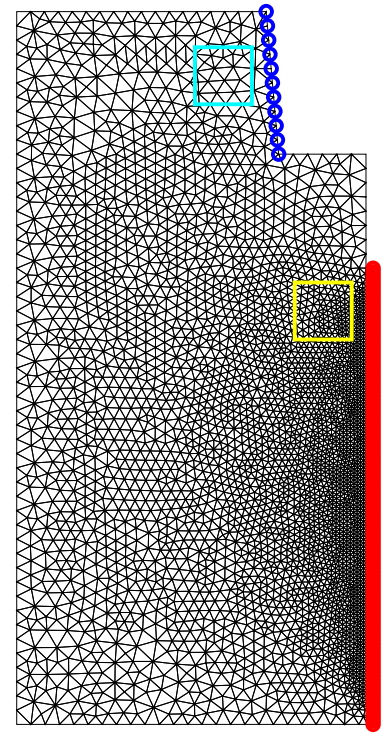

(b)

Figure 17: Finite element mesh of a half sample with (a) coarser (2 mm elements) and (b) finer ( $0.5 \mathrm{~mm}$ elements in the propagation region) discretizations. The blue nodes undergo the effect of a uniform pressure. Dirichlet boundary conditions are gradually relaxed to simulate different propagation steps. The cyan and yellow boxes mimic optical gauges for NOD and CMOD evaluations

For each of the propagation steps, the NODs and CMODs shown in Figure 18 were calculated from the mean displacements of the yellow and cyan gauges, respectively. In the present cases, a linear fit describes very well the relationship between the two quantities (i.e., a close to unity R-squared correlation). Let us note that the proportionality coefficients are very close for both discretizations. 


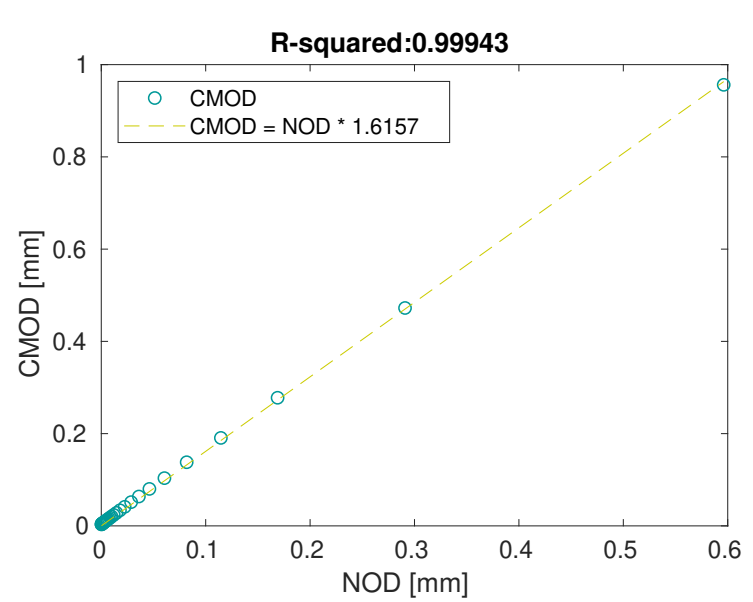

(a)

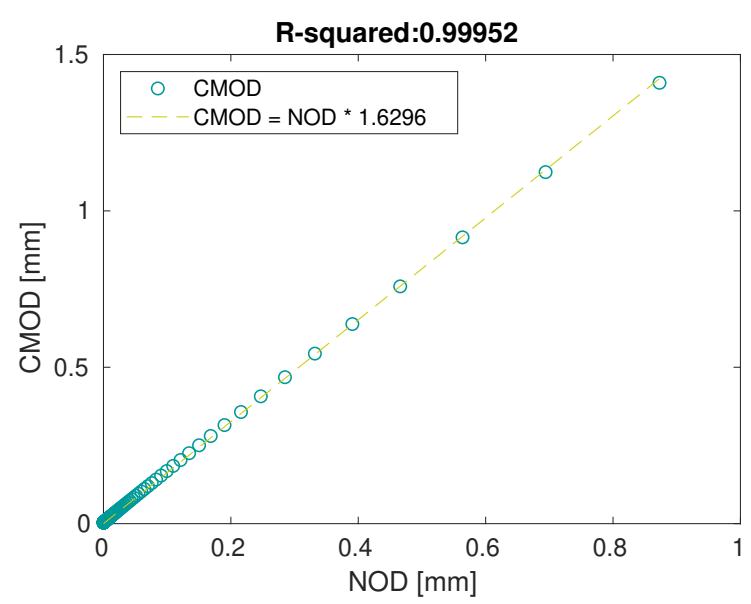

(b)

Figure 18: CMOD vs. NOD curves for the finite element case with (a) coarse and (b) fine discretizations. The linear fit is depicted with yellow dashed lines

\subsection{Evaluations of Fracture Energies from NOD measurements}

The curves reported in Figure 4 are further analyzed to estimate the work of fracture and then the fracture energy by assuming that the fractured surface coincided with the central plane of the ligament for all five tests. The envelope of the vertical load vs. actuator displacement was integrated and divided by twice the projected fracture area (i.e., $2 \times 55 \times 64 \mathrm{~mm}^{2}$ or $2 \times 75 \times 64 \mathrm{~mm}^{2}$ for the cases with or without grooves), considering that one single macrocrack fully propagated throughout the middle vertical plane (Section 4.2), and the results for $\Gamma_{c}^{r a w}$ are shown in Table 6. It is important to highlight that in this case, these calculation include the elastic energy stored in the loading apparatus and is expected to give an overestimation for the material property.

The curves shown in Figure 16(a) were also considered to estimate the work of fracture. The envelope of the horizontal splitting force vs. NOD curves (shown in Figure 19), were extracted and the NOD data were extrapolated for the evaluation of CMODs according to

$$
\mathrm{CMOD}_{F E} \approx \mathrm{NOD} \times 1.62
$$

to extrapolate the CMOD from NOD data to get the fracture energies $\Gamma_{c}^{N O D}$ reported in Table 6. 
Effect of sintering temperature on fracture energy of Alumina-Mullite-Zirconia castable at $600^{\circ} \mathrm{C}$

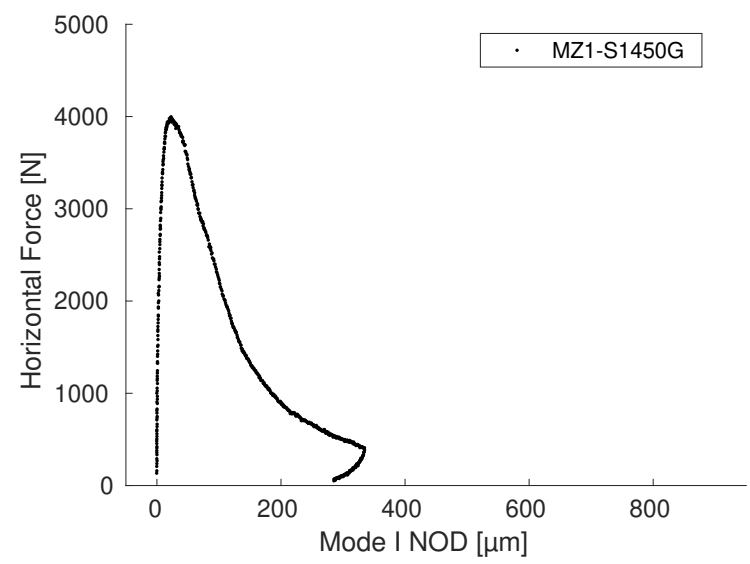

(a)

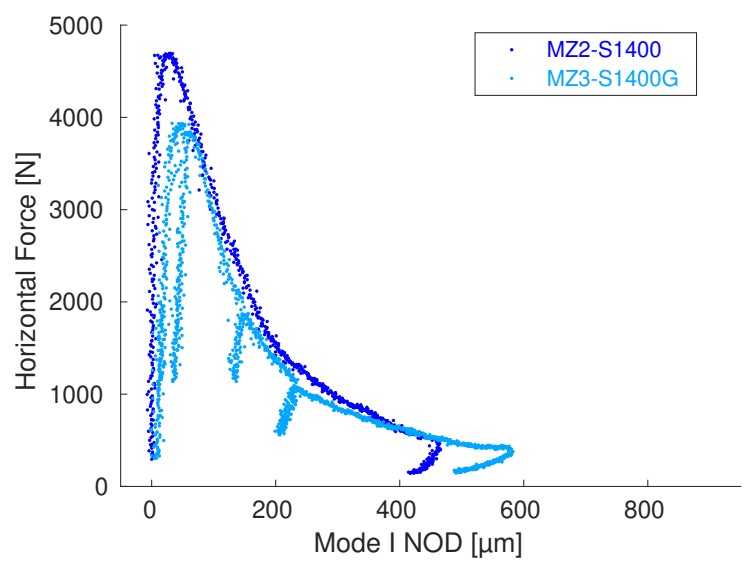

(b)

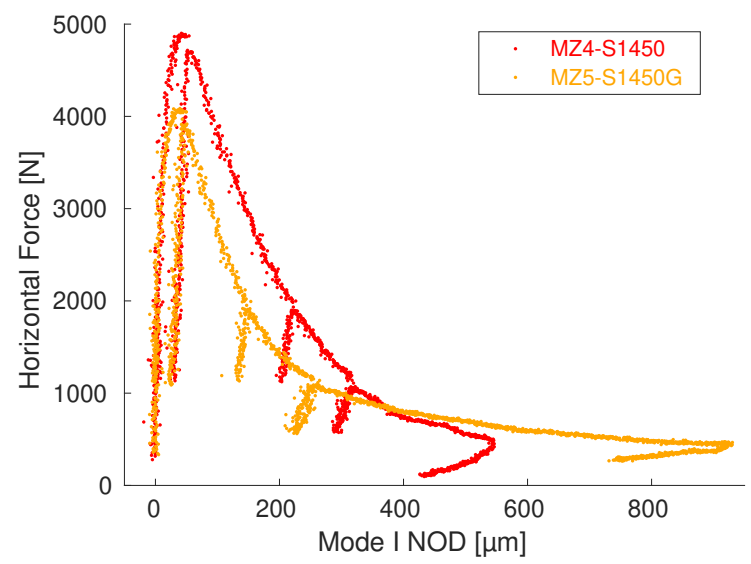

(c)

Figure 19: Envelope of the splitting force vs. NOD for the five tests. (a) Room temperature test. $600^{\circ} \mathrm{C}$ tests with specimens fired at $1400^{\circ} \mathrm{C}(\mathrm{b})$ and $1450^{\circ} \mathrm{C}$ (c).

It is worth mentioning that for the material sintered at $1400^{\circ} \mathrm{C}$, there was a previous estimate at room temperature 204 (i.e., $\Gamma_{c}=85 \pm 40 \mathrm{~J} / \mathrm{m}^{2}$ [46]) consistent with the results reported in Table 6, since $\Gamma_{c}$ is expected to be lower than the 205 reported values for MZ1-S1450G. One further evidence that the present estimations are trustworthy is that, for each 206 test, no level was greater than the upper-bound given by $\Gamma_{c}^{r a w}$. Compared to $\Gamma_{c}^{N O D}, \Gamma_{c}^{r a w}$ is on average $20 \%$ higher. 207 Similar differences were observed for a WST on another castable [22].

\section{Table 6}

Fracture energies (in $\mathrm{J} / \mathrm{m}^{2}$ ) for the five tests evaluated from raw data (Figure 4) as well as DIC measurements (Figure 19 and Equation (1))

\begin{tabular}{|c|c|c|}
\hline Test & $\Gamma_{c}^{\text {raw }}$ & $\Gamma_{c}^{\text {NOD }}$ \\
\hline \hline MZ1-S1450G & 143 & 106 \\
\hline MZ2-S1400 & 227 & 191 \\
\hline MZ3-S1400G & 187 & 153 \\
\hline MZ4-S1450 & 264 & 227 \\
\hline MZ5-S1450G & 254 & 205 \\
\hline
\end{tabular}

Wittmann et al. [11] studied the differences of grooved and non-grooved samples. The authors stated that for 209 grooved samples, since the crack path is pre-defined by the geometry, it does not follow the weakest path and thereby $\mathbf{2 1 0}$ consumes less energy than the non-grooved cases in which the crack path is mostly controlled by heterogeneities and $\mathbf{2 1 1}$ 
thus more energy is consumed by "shear retaining capability of skew cracks and by aggregate interlocking." This 212 statement is consistent with the results shown in Table 6, whereby grooved cases showed 10\% to 20\% smaller fracture $\mathbf{2 1 3}$ energies when compared to the similar non-grooved case.

From the present results, it is observed that a $50{ }^{\circ} \mathrm{C}$ higher firing temperature led to a $25 \%$ increase in the fracture $\mathbf{2 1 5}$ energy $\Gamma_{c}$, which is significant. Since the reproducibility of the tests was very good, it is believed that this effect is real. 216 The influence of the groove was also diminished since the MZ4-S1450 and MZ5-S1450G samples showed similar $\Gamma_{c} \quad 217$ (less than 10\% difference), while MZ2-S1400 and MZ3-S1450G specimens had more than 20\% difference in $\Gamma_{c}$, which 218 is explained by the smaller cohesion related to the lower sintering temperature and consequently higher propensity for 219 initiating cracks.

\section{Conclusion}

The presented tests allowed for the study of the effects of the test temperature, the firing temperature and also about $\mathbf{2 2 2}$ the presence of grooves on the fracture energy of a high-alumina castable with mullite-zirconia aggregates via WSTs. 223 A first conclusion of this set of tests is that when DIC is to be carried out with images acquired at higher temperatures $\mathbf{2 2 4}$ some special care should be taken, since displacement fluctuations can be considerably higher due to heat haze (i.e., 225 up to a ten fold factor in the present case). This effect makes DIC very challenging, and it is expected to worsen when $\mathbf{2 2 6}$ $\begin{array}{ll}\text { the temperature further increases and black body radiations would also appear above } 800^{\circ} \mathrm{C} \text {. } & \mathbf{2 2 7}\end{array}$

Higher peak loads were achieved for the $1450{ }^{\circ} \mathrm{C}$ treatment, and a small increment is seen when comparing the 228 room temperature test to a similar sample at $600{ }^{\circ} \mathrm{C}$ (i.e., MZ1-S1450G and MZ5-S1450G), but that could be related 229 to random variations. Overall, the tests performed at $600{ }^{\circ} \mathrm{C}$ showed larger displacements, especially in the post-peak 230 regime. Although the vertical load vs. actuator displacement curves (Figure 16(a)) show different initial slopes, the 231 horizontal force vs. mode I NOD (Figure 16(b)) showed that the slopes were similar as expected since the Young's 232 modulus of the material is not expected to considerably change for temperatures less than that of the firing process [53- 233 55].

Non-grooved samples were scanned post-mortem in an X-Ray tomograph. Even if crack branching could be seen 235 on the surface thanks to DIC results, the reconstructed volumes showed that a single macrocrack propagated close to 236 the central plane in the bulk, and that branching only occurred very close to the surface. From these observations, 237 the fractured surface was considered identical for all five tests, with the sole difference coming from the presence or $\mathbf{2 3 8}$ absence of lateral grooves. DIC enabled for the calculation of the work of fracture at higher temperatures and infer that 239 more energy was needed to propagate the crack at $600{ }^{\circ} \mathrm{C}$ in the studied material. A $50{ }^{\circ} \mathrm{C}$ higher firing temperature $\mathbf{2 4 0}$ led to a $25 \%$ increase in the fracture energy, which is explained by the smaller cohesion related to the lower sintering $\mathbf{2 4 1}$ temperature and consequently higher propensity for initiating cracks.

These results highlight the importance of performing high-temperature tests to achieve a better understanding of $\mathbf{2 4 3}$ the material and also for more trustworthy material parameters for thermomechanical simulations. If DIC were not $\mathbf{2 4 4}$ used, and only the raw results from the testing machine were utilized, the work of fracture would be overestimated (i.e., 245 $20 \%$ on average in the present case) since it does not distinguish the energy stored in the testing machine from that $\mathbf{2 4 6}$ needed to propagate cracks. Further, a simple numerical analysis was performed to extrapolate the measured notch $\mathbf{2 4 7}$ opening displacements to crack mouth opening displacements needed to compute the work of fracture. More extensive 248 studies are needed to account for nonlinear cohesive effects [25] that were neglected herein. To avoid such step, and $\mathbf{2 4 9}$ if the main objective of the tests is to evaluate the work of fracture, it is advised to focus in an area enabling the crack $\mathbf{2 5 0}$ mouth opening displacement to be measured.

\section{Acknowledgments}

This study was financed in part by the Coordenação de Aperfeiçoamento de Pessoal de Nível Superior - Brasil 253 (CAPES) - Finance Code 001 CAPES (Brazil) and \#2018/15266-0, \#2018/23081-0, and \#2018/02801-4, São Paulo Research Foundation (FAPESP).

\section{Credit authorship statement}

R. Vargas: Conceptualization, Methodology, Investigation, Software, Original draft preparation, Writing - Review \& Editing 
Effect of sintering temperature on fracture energy of Alumina-Mullite-Zirconia castable at $600^{\circ} \mathrm{C}$

X. Pinelli: Investigation (WSTs)

B. Smaniotto: Investigation (tomography)

F. Hild: Supervision, Conceptualization, Methodology, Software, Formal analysis, Writing - Review \& Editing, 261 Resources, Funding acquisition, Project administration

R.B. Canto: Supervision, Conceptualization, Writing - Review \& Editing, Resources, Funding acquisition, Project 263 administration

\section{Declaration of Competing Interest}

The authors declare that they have no known competing financial interests or personal relationships that could have 266 appeared to influence the work reported in this paper.

\section{References}

[1] J. Wachtman, Materials and Equipment - Whitewares - Refractory Ceramics - Basic Science: Ceramic Engineering and Science Proceedings, 269 Volume 16, no. 1 in Ceramic Engineering and Science Proceedings, Wiley, 2009.

[2] W. E. Lee, W. Vieira, S. Zhang, K. Ghanbari Ahari, H. Sarpoolaky, C. Parr, Castable refractory concretes, International Materials Reviews 46 (3) (2001) 145-167.

[3] W. E. Lee, R. E. Moore, Evolution of in situ refractories in the 20th century, Journal of the American Ceramic Society 81 (6) (1998) 1385-1410. 273

[4] P. Luz, A., A. L. Braulio, M., C. Pandolfelli, V., Refractory Castable Engineering, 1st Edition, Vol. 1, Göller Verlag, São Carlos, SP, 2015.

[5] E. Tschegg, Prüfeinrichtung zur Ermittlung von bruchmechanishen Kennwerten sowie hiefür geeignete, Prüfkörper, Austrian Pat. AT 390328B, registered (1986).

6] H. N. Linsbauer, E. K. Tschegg, Fracture energy determination of concrete with cube shaped specimens, Zement und Beton 31 (1986) 38-40.

[7] E. Brühwiler, F. H. Wittmann, The wedge splitting test, a new method of performing stable fracture mechanics tests, Engineering Fracture Mechanics 35 (1-3) (1990) 117-125.

[8] H. Harmuth, Stability of crack propagation associated with fracture energy determined by wedge splitting specimen, Theoretical and Applied Fracture Mechanics 23 (1995) 103-108.

[9] S. Ribeiro, C. C. D. Exposito, J. A. Rodrigues, Projeto, adaptação, instalação e testes preliminares para um sistema de medida de energia de fratura de materiais cerâmicos pelo método da cunha, Cerâmica 54 (2008) 418-426.

[10] H. Harmuth, K. Rieder, M. Krobath, E. Tschegg, Investigation of the nonlinear fracture behaviour of ordinary ceramic refractory materials, Materials Science and Engineering: A 214 (1-2) (1996) 53-61.

[11] F. Wittmann, V. Slowik, A. Alvaredo, Probabilistic aspects of fracture energy of concrete, Materials and Structures 27 (9) (1994) $499-504$.

[12] J. Poirier, E. Blond, E. Bilbao, R. Michel, A. Coulon, J. Gillibert, M. Boussuge, Y. Zhang, D. Ryckelynk, G. Dusserre, T. Cutard, P. Leplay, New advances in the laboratory characterization of refractories: testing and modelling, Metallurgical Research \& Technology 114 (6) (2017) 610.

[13] M. A. Sutton, J. J. Orteu, H. Schreier, Image correlation for shape, motion and deformation measurements: Basic concepts, theory and applications, Springer Science \& Business Media, 2009.

[14] F. Hild, S. Roux, Digital Image Correlation, Wiley-VCH, Weinheim (Germany), 2012, pp. 183-228.

[15] M. A. Sutton, Computer vision-based, noncontacting deformation measurements in mechanics: A generational transformation, Applied Mechanics Reviews 65 (AMR-13-1009, 050802) (2013).

[16] Y. Belrhiti, O. Pop, A. Germaneau, P. Doumalin, J. C. Dupré, H. Harmuth, M. Huger, T. Chotard, Investigation of the impact of micro-cracks on fracture behavior of magnesia products using wedge splitting test and digital image correlation, Journal of the European Ceramic Society 35 (2) (2015) 823-829.

[17] R. Vargas, J. Neggers, R. B. Canto, J. A. Rodrigues, F. Hild, Analysis of wedge splitting test on refractory castable via integrated DIC, Journal of the European Ceramic Society 36 (16) (2016) 4309-4317.

[18] Y. Dai, D. Gruber, H. Harmuth, Observation and quantification of the fracture process zone for two magnesia refractories with different brittleness, Journal of the European Ceramic Society 37 (6) (2017) 2521-2529.

[19] Y. Dai, D. Gruber, H. Harmuth, Determination of the fracture behaviour of MgO-refractories using multi-cycle wedge splitting test and digital image correlation, Journal of the European Ceramic Society 37 (15) (2017) 5035-5043.

[20] J. C. Dupré, P. Doumalin, Y. Belrhiti, I. Khlifi, O. Pop, M. Huger, Detection of cracks in refractory materials by an enhanced digital image correlation technique, Journal of Materials Science 53 (2) (2018) 977-993.

[21] Y. Dai, Y. Yin, X. Xu, S. Jin, Y. Li, H. Harmuth, Effect of the phase transformation on fracture behaviour of fused silica refractories, Journal of the European Ceramic Society 38 (16) (2018) 5601-5609.

[22] R. Vargas, J. Neggers, R. B. Canto, J. A. Rodrigues, F. Hild, Comparison of two full-field identification methods for the wedge splitting test on a refractory, Journal of the European Ceramic Society 38 (16) (2018) 5569 - 5579.

[23] I. Khlifi, O. Pop, J.-C. Dupré, P. Doumalin, M. Huger, Investigation of microstructure-property relantionships of magnesia-hercynite refractory composites by a refined digital image correlation technique, Journal of the European Ceramic Society 39 (13) (2019) $3893-3902$.

[24] Y. Dai, Y. Li, X. Xu, Q. Zhu, Y. Yin, S. Ge, A. Huang, L. Pan, Characterization of tensile failure behaviour of magnesia refractory materials by a modified dog-bone shape direct tensile method and splitting tests, Ceramics International (2019).

[25] R. Vargas, J. Neggers, R. B. Canto, J. A. Rodrigues, F. Hild, Analysis of a castable refractory using the wedge splitting test and cohesive zone model, Journal of the European Ceramic Society 39 (13) (2019) 3903-3914. 
[26] J. Lyons, J. Liu, M. Sutton, High-temperature deformation measurements using digital-image correlation, Experimental Mechanics 36 (1) 316 (1996) 64-70.

[27] M. Novak, F. Zok, High-temperature materials testing with full-field strain measurement: Experimental design and practice, Review of Si- $\mathbf{3 1 8}$ centific Instruments 82 (11) (2011) 115101.

[28] J. Hammer, J. Seidt, A. Gilat, Strain measurement at temperatures up to $800^{\circ} \mathrm{c}$ utilizing digital image correlation, in: H. Jin, C. Sciammarella, 320 S. Yoshida, L. Lamberti (Eds.), Advancement of Optical Methods in Experimental Mechanics, Volume 3: Conference Proceedings of the 321 Society for Experimental Mechanics Series, Springer International Publishing, 2014, pp. 167-170.

[29] M. Berny, T. Archer, A. Mavel, P. Beauchêne, S. Roux, F. Hild, On the analysis of heat haze effects with spacetime DIC, Optics and Lasers in 323 Engineering 111 (2018) 135-153.

[30] T. Archer, P. Beauchêne, C. Huchette, F. Hild, Global digital image correlation up to very high temperatures with grey level corrections, 325 Measurement Science and Technology 31 (2) (2019) 024003.

[31] B. Grant, H. Stone, P. Withers, M. Preuss, High-temperature strain field measurement using digital image correlation, Journal of Strain Analysis 327 for Engineering Design 44 (4) (2009) 263-271.

[32] B. Pan, D. Wu, Y. Xia, High-temperature deformation field measurement by combining transient aerodynamic heating simulation system and 329 reliability-guided digital image correlation, Optics and Lasers in Engineering 48 (9) (2010) 841-848.

\section{(} Measurement Science and Technology 22 (1) (2011) 015701.

[34] P. Leplay, O. Lafforgue, F. Hild, Analysis of asymmetrical creep of a ceramic at $1350{ }^{\circ} \mathrm{C}$ by Digital Image Correlation, Journal of the American Ceramic Society 98 (7) (2015) 2240-2247.

[35] M. De Strycker, L. Schueremans, W. Van Paepegem, D. Debruyne, Measuring the thermal expansion coefficient of tubular steel specimens with digital image correlation techniques, Optics and Lasers in Engineering 48 (10) (2010) 978-986.

[36] H. Harmuth, E. K. Tschegg A fracture mechanics approach for the development of refractory materials with reduced brittleness, Fatigue \& 337 Fracture of Engineering Materials \& Structures 20 (11) (1997) 1585-1603.

[37] G. Buchebner, T. Molinari, D. Rumpf, Developing basic high-performance products for furnaces in the nonferrous metals industries, JOM 52 (2) (2000) 68-72.

[38] P.-Y. Brisson, E. Paransky, M. Rigaud, Effects of andalusite grain size on microstructure and mechanical properties of low cement aluminabased castables, Canadian metallurgical quarterly 42 (2) (2003) 157-165.

[39] K. Andreev, V. Tadaion, Q. Zhu, W. Wang, Y. Yin, T. Tonnesen, Thermal and mechanical cyclic tests and fracture mechanics parameters as indicators of thermal shock resistance-case study on silica refractories, Journal of the European Ceramic Society 39 (4) (2019) $1650-1659$.

[40] M. Stückelschweiger, D. Gruber, S. Jin, H. Harmuth, Wedge-splitting test on carbon-containing refractories at high temperatures, Applied Sciences 9 (16) (2019) 3249.

[41] E. Brochen, C. Dannert, P. Quirmbach, Thermo-mechanical characterisation of magnesia-carbon refractories by means of wedge splitting test under controlled atmosphere at high-temperature, in: Proceedings of the Unified International Technical Conference on Refractories (UNITECR 2013), Wiley Online Library, 2014, pp. 53-58.

[42] A. Doitrand, R. Estevez, M. Thibault, P. Leplay, Fracture and cohesive parameter identification of refractories by Digital Image Correlation up to $1200^{\circ} \mathrm{C}$, Experimental Mechanics (2020).

[43] Z. Pan, S. Huang, Y. Su, M. Qiao, Q. Zhang, Strain field measurements over $3000^{\circ} \mathrm{C}$ using 3D-digital image correlation, Optics and Lasers in Engineering 127 (2020) 105942.

[44] R. C. Garvie, R. H. Hannink, R. T. Pascoe, Ceramic steel?, Nature 258 (5537) (1975) 703-704.

[45] R. H. J. Hannink, P. M. Kelly, B. C. Muddle, Transformation toughening in zirconia-containing ceramics, Journal of the American Ceramic Society 83 (3) (2000) 461-487.

[46] C. Jailin, A. Bouterf, R. Vargas, F. Hild, S. Roux, Sub-minute in situ Fracture Test in a Lab CT-scanner, Integrating Materials and Manufacturing Innovation 8 (3) (2019) 413-422.

[47] M. C. Greca, J. V. Emiliano, A. M. Segadães, Revised phase equilibrium relationships in the system $\mathrm{Al}_{2} \mathrm{O}_{3}-\mathrm{ZrO}_{2}-\mathrm{SiO}_{2}, \mathrm{Journal}_{\text {of }}$ the European Ceramic Society 9 (4) (1992) 271-283.

[48] D. Y. Miyaji, T. Tonnesen, J. A. Rodrigues, Fracture energy and thermal shock damage resistance of refractory castables containing eutectic aggregates, Ceramics International 40 (9, Part B) (2014) 15227-15239.

[49] H. Leclerc, J. Périé, S. Roux, F. Hild, Integrated digital image correlation for the identification of mechanical properties, in: A. Gagalowicz, W. Philips (Eds.), MIRAGE 2009, Vol. LNCS 5496, Springer, Berlin (Germany), 2009, pp. 161-171.

[50] H. Leclerc, J. Neggers, F. Mathieu, F. Hild, S. Roux, Correli 3.0, IDDN.FR.001.520008.000.S.P.2015.000.31500, Agence pour la Protection des Programmes, Paris (France) (2015).

[51] F. Hild, S. Roux, Digital image correlation, in: P. Rastogi, E. Hack (Eds.), Optical Methods for Solid Mechanics. A Full-Field Approach, Wiley-VCH, Weinheim (Germany), 2012, pp. 183-228.

[52] F. Hild, A. Bouterf, S. Roux, Damage measurements via DIC, International Journal of Fracture 191 (1-2) (2015) 77-105.

[53] E. Gregorová, W. Pabst, V. Nečina, T. Uhlîrová, P. Diblíková, Young’s modulus evolution during heating, re-sintering and cooling of partially sintered alumina ceramics, Journal of the European Ceramic Society 39 (5) (2019) 1893-1899.

[54] E. Gregorová, V. Nečina, S. Hříbalová, W. Pabst, Temperature dependence of Young's modulus and damping of partially sintered and dense zirconia ceramics, Journal of the European Ceramic Society 40 (5) (2020) 2063-2071.

[55] R. Vargas, J. Alves Júnior, J. Rodrigues, F. Hild, J. Baldo, R. Canto, Influence of thermal cycles on Young's modulus of a refractory with mullite-zirconia aggregates, Submitted for publication (2020). 